\title{
VEINTE PROPUESTAS PARA FORTALEGER EL FEDERALISMO ARGENTINO
}

\section{Antonio María HeRnÁNDEZ*}

SUMARIO: I. Introducción. II. Cumplir los principios del sistema republicano y federal de la Constitución nacional. III. Terminar con el hiperpresidencialismo. IV. Fortalecer el rol federal del Congreso y del Senado de la Nación, en particular. V. Reafirmar el rol de la Corte Suprema de Justicia de la Nación como garante del federalismo. VI. Promover un nuevo ordenamiento territorial del país que modifique la enorme concentración de poder político, económico, demográfico y cultural en el área metropolitana de Buenos Aires. VII. Sancionar la ley convenio de coparticipación impositiva, de conformidad con los principios constitucionales. VIII. Respetar los principios federales en la sanción anual de los presupuestos. IX. Federalizar el Banco Central. X. Afianzar el federalismo de coordinación o concertación mediante un mejor ejercicio de relaciones interjurisdiccionales. Creación de una Asociación o Conferencia Nacional de Gobernadores. XI. Realizar una planificación federal para el desarrollo del país, con participación de los distintos niveles estaduales. XII. Promover las regiones para el desarrollo económico y social. XIII. Impulsar el nuevo rol de regiones, provincias y municipios en los procesos de integración nacional y supranacional. XIV. Fortalecer las autonomías provinciales, de la Ciudad Autónoma de Buenos Aires y de los municipios. XV. Modificar o derogar la legislación centralista vigente y las políticas respectivas. XVI. Federalizar la educación. XVII. Ejercer un federalismo de concertación para la exploración, explotación y aprovechamiento de los recursos naturales. XVIII. Federalizar los servicios públicos de competencia nacional. XIX. Afianzar los principios federales en la doctrina y organización de los partidos políticos. XX. Descentralizar e integrar el país en otros aspectos. XXI. Trasladar la Capital Federal. XXII. Conclusión.

\section{INTRODUGCIÓN}

El federalismo argentino se caracteriza por una fuerte tendencia a la centralización, más allá de lo dispuesto por la Constitución Nacional, que espe-

* Profesor de derecho constitucional y derecho público provincial y municipal de la Universidad Nacional de Córdoba; director del Instituto de Federalismo de la Academia Nacional de Derecho y Ciencias Sociales de Córdoba; presidente honorario de la Asociación Argentina de Derecho Constitucional y exconvencional constituyente de la Nación.

Boletín Mexicano de Derecho Comparado nueva serie, año XLIX, núm. 146, mayo-agosto de 2016, pp. 375-418.

D. R. C 2016. UNAM, Instituto de Investigaciones Jurídicas. 
Esta revista forma parte del acervo de la Biblioteca Jurídica Virtual del Instituto de Investigaciones Jurídicas de la UNAM

cialmente a la luz de la última reforma constitucional de 1994 ha intentado profundizar la descentralización del poder. Nos hemos ocupado en señalar la distancia existente entre el federalismo "normativo" y el "real", vigente o sociológico y la necesidad de producir un avance en esta materia, para dar cumplimiento a los mandatos, principios y valores de nuestra ley suprema. Estamos convencidos de que Argentina podría consumar un enorme avance institucional, político y social si se hiciera realidad el proyecto federal de la Constitución.

En este trabajo explicitamos algunas de las propuestas antes formuladas en nuestras obras anteriores Federalismo, autonomía municipal y Ciudad de Buenos Aires en la reforma constitucional de 1994 (Buenos Aires, Depalma, 1997); Federalismo y constitucionalismo provincial (Buenos Aires, Abeledo-Perrot, 2009) y Fortalezas y debilidades constitucionales. Una lectura crítica en el Bicentenario (Buenos Aires, Abeledo-Perrot, 2012) y agregamos otras más, para tratar de comprender la máxima cantidad de aspectos de esta compleja temática.

Las veinte propuestas no son taxativas, ni hemos formulado un orden de importancia de ellas, destacando, asimismo, que existen profundas interrelaciones entre ellas. Creemos que algunas pueden servir también para fortalecer el federalismo mexicano, habida cuenta de la similitud de problemas que enfrentamos en nuestros respectivos países, que también son democráticos, republicanos y federales.

\section{GUMPLIR LOS PRINCIPIOS DEL SISTEMA REPUBLICANO Y FEDERAL DE LA CONSTITUGIÓN NAGIONAL}

Es necesario mejorar nuestra calidad institucional mediante el cumplimiento de los principios y normativa de nuestro sistema republicano y federal, establecidos en la Constitución Nacional. En este sentido, debe superarse la anomia que padecemos, como expresión de nuestros problemas en materia de cultura democrática, política y constitucional. ${ }^{1}$

1 Véase la obra Encuesta de cultura constitucional. Argentina: una sociedad anómica, de Antonio María Hernández, Daniel Zovatto y Manuel Mora y Araujo, editado en México por la Universidad Nacional Autónoma de México, Idea Internacional y la Asociación Argentina de Derecho Constitucional, 2005. Y en cuanto al estudio de la anomia, obsérvese el libro de Carlos Santiago Nino, Un país al margen de la ley, Buenos Aires, Emecé, 1992. 
Esta revista forma parte del acervo de la Biblioteca Jurídica Virtual del Instituto de Investigaciones Jurídicas de la UNAM

Entre las medidas que hemos propuesto al respecto ${ }^{2}$ es menester poner el énfasis en la educación cívica y democrática, asentada en los valores y principios de la Constitución Nacional, tal como lo dispone la Ley 25,863, que también se incumple. ${ }^{3}$

Existe la necesidad imperiosa de consolidar el buen funcionamiento de los sistemas republicanos, con división y equilibrio de poderes, para el logro de sociedades abiertas y democráticas, con una elevación de la cultura constitucional y de la legalidad.

Tal como lo hemos afirmado, ${ }^{4}$ hay una convergencia de objetivos entre el sistema republicano como forma de gobierno y el federalismo como forma de Estado: asegurar la libertad y los derechos de los hombres y limitar el poder. Allí reside la interacción entre ambos términos.

El sistema republicano tiene entre sus caracteres el reconocimiento de la libertad e igualdad de los hombres y la división horizontal de poderes, como lo sostuvieron Locke y Montesquieu. El federalismo - como una forma de descentralización del poder que sólo se concibe en un régimen político democrático - acerca el poder a los ciudadanos y asegura doblemente sus derechos, además del control respectivo entre ambos órdenes gubernamentales, como expresara Madison. ${ }^{5}$

Asimismo, comentamos que ya hemos presentado la Segunda Encuesta de Cultura Constitucional en abril de 2015, bajo la dirección de Hernández, Zovatto y Eduardo Fidanza.

2 En nuestra obra Fortalezas y debilidades constitucionales, pp. 158 y ss.

3 La Ley fue sancionada en 2003 por el Congreso de la Nación y promulgada el 8 de enero de 2004 por el presidente de la República. Se declaró al 1o. de mayo como Día de la Constitución Nacional, y se dispuso la enseñanza de la misma en los diversos niveles educativos. La norma fue una iniciativa de la Asociación Argentina de Derecho Constitucional, que presidíamos.

4 Hernández, Antonio María, Federalismo y constitucionalismo provincial, Buenos Aires, Abeledo-Perrot, 2009, cap. IX, "Gobierno legislativo y ejecutivo en los países federales", pp. 283 y 284.

5 "En una república unitaria - decía James Madison en El Federalista, núm. 51 - todo el poder cedido por el pueblo se coloca bajo la administración de un solo gobierno, y se evitan las usurpaciones dividiendo a ese gobierno en departamentos separados y diferentes. En la compleja república americana, el poder de que se desprende el pueblo se divide primeramente entre dos gobiernos distintos, y luego la porción que corresponde a cada uno se subdivide entre departamentos diferentes y separados. De aquí surge una doble seguridad para los derechos del pueblo. Los diferentes gobiernos se tendrán a raya unos a otros, al propio tiempo que cada uno se regulará por sí mismo", Hamilton et al., El Federalista, México, Fondo de Cultura Económica, 2006, pp. 221 y 222. Por eso Loewenstein señalaba el control vertical del poder existente en el federalismo. 
Esta revista forma parte del acervo de la Biblioteca Jurídica Virtual del Instituto de Investigaciones Jurídicas de la UNAM

Vigorosas autonomías provinciales y municipales presuponen una participación activa de los ciudadanos para tener buenos gobiernos, y además conllevan una limitación del poder del gobierno nacional.

\section{TERMINAR GON EL HIPERPRESIDENCIALISMO}

Para nosotros, resulta fundamental afirmar la tendencia hacia presidencialismos atenuados, racionales y controlados, que se observa en las reformas constitucionales producidas en América Latina, incluida la nuestra de 1994.

No dudamos que una vigencia plena de la Constitución Nacional - como lo hemos sostenido insistentemente - significará una más que notoria atenuación del hiperpresidencialismo.

El fortalecimiento del Congreso y del Poder Judicial en sus funciones de control resultarán determinantes para el logro de tan importante objetivo, así como también el efectivo funcionamiento de las autonomías provinciales y municipales, como controles verticales del poder.

Pero esto conlleva la necesidad de producir trascendentes cambios legislativos e institucionales, entre los que se destacan los vinculados a los decretos de necesidad y urgencia, a los superpoderes en materia de administración financiera, a la finalización de la legislación de emergencia, etcétera. ${ }^{6}$

La complejidad del problema del hiperpresidencialismo en sus aspectos "corporativos" y "delegativos" requerirá inteligencia, alta dosis de docencia y gran determinación política para impulsar los cambios imprescindibles, ya que deberán afectarse intereses de poderosos sectores políticos, sindicales y empresariales.

Habrá que demostrar un especial valor para desmontar sistemas de privilegios corporativos y de corrupción, que han herido los principios de nuestro sistema republicano y del Estado constitucional y democrático de derecho.

6 Hemos estudiado estos temas en la obra colectiva que dirigimos Derecho constitucional, 2 tomos, Buenos Aires, La Ley, 2012, específicamente en el cap. XVII de nuestra autoría sobre "Poder Ejecutivo".

7 Como lo estudiara Carlos Santiago Nino en su obra Fundamentos de derecho constitucional, Buenos Aires, Astrea, 1992.

8 Según el conocido análisis efectuado por el politólogo Guillermo O’Donnell. 
Esta revista forma parte del acervo de la Biblioteca Jurídica Virtual del Instituto de Investigaciones Jurídicas de la UNAM

\section{ForTALEGER EL ROL FEDERAL DEL CONGRESO Y DEL SENADO DE LA NAGIÓN, EN PARTIGULAR}

Podemos señalar que en ambas cámaras —en una valoración institucional general -9 no ha existido una adecuada defensa de los principios federales y de los intereses regionales y provinciales, ya que han primado las políticas fijadas por los presidentes y los partidos políticos, que en no pocas oportunidades han tendido a la centralización del poder.

Esto es muy grave, en particular para el Senado, que es un órgano federal por antonomasia. ${ }^{10}$ Así lo expresó con particular elocuencia en esa propia Cámara, Alfredo Palacios: ${ }^{11}$

Soy representante de la capital de la República. He nacido en esta urbe fastuosa y cosmopolita que ignora el dolor argentino, la desolación de la tierra yerma y la tragedia de los hombres de los eriales desiertos y silenciosos... Hemos de resolver el encadenamiento de problemas planteados por provincias pobres, sin mezquindades ni regateos, pues de otra manera conoceremos a las provincias como organizaciones políticas, pero ignoraremos a las regiones que tienen características sociales étnicas propias.

Y luego propuso que los senadores de las provincias del interior asumieran su condición de defensores de esas regiones. ${ }^{12}$

9 Que importa dejar a salvo el accionar de legisladores y partidos que actuaron con otros criterios, y que por razones de brevedad no podemos analizar.

10 Desde lo doctrinario, véanse, entre otros estudios al respecto, Frías, Pedro J., Introducción al derecho público provincial, Buenos Aires, Depalma, 1980, pp. 96 y ss.; los dos dictámenes del Consejo de Consolidación de la Democracia, el preliminar de 1986 y el segundo dictamen de 1987, publicados por Eudeba, Buenos Aires; Douglas Price, Jorge y Rosenkrantz, Carlos, Las cuestiones del federalismo. Análisis de la reforma constitucional desde la perspectiva del federalismo comparado, CFI, 1993, t. 1, pp. 90 y ss.; Luna, Eduardo, Congreso y control, Mendoza, Ediciones Jurídicas Cuyo, 2007; Barrera Buteler, Guillermo, "Aspectos políticos del federalismo", punto 3, "El Senado desvirtuado" en el libro Aspectos históricos y políticos del federalismo argentino, director Antonio María Hernández, Instituto de Federalismo de la Academia Nacional de Derecho y Ciencias Sociales de Córdoba, 2009, pp 282 y ss.; Garat, Pablo, “¿El presidencialismo terminará con el federalismo?", Revista Civilidad, edición núm. 33, agosto de 2013, pp. 8 y ss., y Hernández, Antonio María, "Federalismo, autonomía municipal y ciudad de Buenos Aires en la reforma constitucional de 1994", y "Federalismo y constitucionalismo provincial", obras ya citadas, además de "Aspectos históricos y políticos del federalismo argentino", Aspectos históricos y políticos del federalismo argentino, cit.

11 En la sesión del 27 de agosto de 1941.

12 En su publicación Pueblos desamparados. Solución de los problemas del noroeste argentino, Buenos Aires, Kraft, 1944. Por nuestra parte, desde hace tiempo sostenemos lo propio, 
Esta revista forma parte del acervo de la Biblioteca Jurídica Virtual del Instituto de Investigaciones Jurídicas de la UNAM

No obstante que la reforma de 1994 introdujo importantes cambios en el Senado, en su forma de elección, integración, término de mandato y competencias, todavía no se observó un adecuado cumplimiento de dicho rol federal y de defensa de las autonomías provinciales. ${ }^{13}$ Recuérdese en particular que se ha determinado que este cuerpo sea la cámara de origen en las leyes de coparticipación impositiva ${ }^{14}$ y en las destinadas al crecimiento armónico de la nación, al poblamiento de su territorio y a la promoción de políticas diferenciadas que tiendan a equilibrar el desigual desarrollo relativo de provincias y regiones. ${ }^{15}$

Tal como lo dijimos anteriormente, la cuestión se vincula a nuestro sistema político, donde las decisiones se toman principalmente por el presidente con el apoyo de los gobernadores provinciales, que influyen en los respectivos diputados y senadores de la nación.

Un ejemplo notorio es el tratamiento de los temas de coparticipación impositiva y de responsabilidad fiscal de las provincias - de especial importancia para nuestro federalismo- , ya que en lugar de un debate amplio, transparente y participativo sólo se advierten negociaciones entre el presidente y cada uno de los gobernadores, con un resultado que afecta las autonomías provinciales, los principios constitucionales y el papel del Congreso y del Senado en particular.

Los gobernadores en general responden a las directivas políticas del presidente en detrimento de los intereses y poderes provinciales.

A lo largo del tiempo se ha consolidado el hiperpresidencialismo, que ha subordinado tanto al Congreso como a las provincias, que presentan un alto grado de dependencia política y económica. ${ }^{16}$

promoviendo el accionar conjunto de los legisladores federales para fortalecer las regiones. Véase la nota 95, donde referimos nuestras publicaciones al respecto, y en particular, a la región centro.

13 Hernández, Antonio María, "Federalismo y constitucionalismo provincial", cit., cap. III: "El federalismo en la reforma constitucional de 1994", en el punto "Aspectos institucionales y políticos del federalismo", 3. "El Senado y su rol federal”, pp. 64 y ss.

14 Como lo establece el artículo 75, inciso 2, de la Constitución Nacional.

15 Ibidem, inciso 19 de la Constitución Nacional.

16 Hernández, Antonio María, "Sobre presidencialismo y federalismo en la República Argentina", cap. VIII de su obra Federalismo y constitucionalismo provincial, cit., pp. 253 y ss. Para un análisis de la importancia del Congreso en nuestra Federación, véanse los trabajos de Armagnague, Juan Fernando, "El Congreso y el federalismo" (pp. 29 y ss.) y de Riberi, Pablo, "El Congreso Nacional frente a los conflictos federales: ¿protagonista o actor de 
Esta revista forma parte del acervo de la Biblioteca Jurídica Virtual del Instituto de Investigaciones Jurídicas de la UNAM

\section{ReAFirmar EL ROL DE LA CORTE SUPREMA DE JUSTICIA DE LA NACIÓN COMO GARANTE DEL FEDERALISMO}

Es decisivo el rol que cumple el más alto tribunal de una Federación, ya que debe asegurar el cumplimiento de la Constitución, que fija las competencias de los diversos órdenes gubernamentales que la componen.

Esa tarea jurídica y política de alta alcurnia institucional importa mantener el equilibrio entre las fuerzas centrípetas y centrífugas que con mayor razón se presentan en un Estado federal, por la descentralización del poder entre esos diversos órdenes.

Nosotros exhibimos un federalismo marcadamente centralizado, no obstante lo dispuesto por la ley suprema. Y a ese proceso no fue ajena la jurisprudencia de la Corte Suprema de Justicia de la Nación, que convalidó muchos de los avances del gobierno federal, sobre los estados provinciales y locales.

Por ello es menester profundizar el cambio de la jurisprudencia de nuestro más alto tribunal, sobre todo a la luz de la reforma constitucional de 1994, que ha descentralizado nuestra federación, a través de sus grandes capítulos sobre los diversos aspectos del federalismo, con especial fortalecimiento de las autonomías provinciales, de la Ciudad Autónoma de Buenos Aires y de los municipios. ${ }^{17}$

Sin poder detenernos por razones de brevedad en un análisis de la jurisprudencia - marcadamente centralista-, se está advirtiendo en estos tiempos, una modificación de la misma, tendente a consolidar los principios federales. En tal sentido, señalamos los casos "Zavalía José Luis c. Santiago del Estero, Provincia y Estado Nacional s/amparo"(2004) y "Díaz Ruth Inés c. Buenos Aires, Provincia de s/acción declarativa de inconstitucionalidad" (2006), sobre soberanía y autonomía provinciales, ${ }^{18}$

reparto?” (pp. 39 y ss.), en Hernández, Antonio María, Aspectos jurídicos e institucionales del federalismo argentino, Córdoba, Instituto de Federalismo de la Academia Nacional de Derecho y Ciencias Sociales de Córdoba, 2010.

17 Como lo hemos expuesto en profundidad en nuestras obras Federalismo, autonomía municipal y Ciudad de Buenos Aires en la reforma constitucional de 1994, Buenos Aires, Depalma, 1997, y Federalismo y constitucionalismo provincial, Buenos Aires, Abeledo-Perrot, 2009.

18 Véase nuestro comentario "Soberanía y autonomía provinciales en la doctrina y en la jurisprudencia de la CSJN", en el cap. XXXIX de la obra Corte Suprema de Fusticia de la Nación. Máximos precedentes, derecho constitucional, t. IV, director Pablo Manili, Buenos Aires, La Ley, pp. 593 y ss. Aquí el máximo tribunal vuelve a una jurisprudencia originada en el 
Esta revista forma parte del acervo de la Biblioteca Jurídica Virtual del Instituto de Investigaciones Jurídicas de la UNAM

"El Práctico c. Córdoba, Provincia de s/acción declarativa de inconstitucionalidad" (2011), sobre el alcance del poder de policía provincial en el transporte interprovincial, ${ }^{19}$ "Camaronera Patagónica SA c. Ministerio de Economía y otros s/amparo” (2014), sobre principio de legalidad en materia tributaria y limitación de las delegaciones, ${ }^{20}$ "Pedraza Héctor Hugo c. Anses s/acción de amparo" (2014), sobre federalismo y descentralización judicial al posibilitar que las cámaras federales del interior del país intervengan en cuestiones de seguridad social, ${ }^{21}$ y "Rivademar, Angela Martínez Galván de c. Municipalidad de Rosario" (1989), y "Ponce Carlos Alberto" (2005), sobre autonomía municipal. ${ }^{22}$ En torno a esta última cuestión, pero vinculada a los aspectos fiscales y económicos como los de la coparticipación impositiva, debemos destacar muy especialmente el reciente fallo recaído en autos "Intendente Municipal Capital s. amparo",

caso "Resoagli" de 1869, que reconoce esta doble naturaleza para las provincias, como lo hacía la doctrina más autorizada de nuestro país.

19 Especialmente véanse los considerandos 12 a 15 del voto de mayoría, que hacen referencia al federalismo de concertación y además extienden el alcance del poder de policía provincial en una materia como la del transporte interprovincial, donde existía una intervención excluyente del gobierno federal, según la propia jurisprudencia anterior del Tribunal.

20 Este fallo ratifica el principio de legalidad en materia tributaria, limitando las delegaciones efectuadas en violación del artículo 76 de la ley suprema. Esto es muy importante con relación a nuestro sistema republicano, a la atenuación del hiperpresidencialismo, a las emergencias y también al federalismo, ya que en el Congreso se encuentra la representación de las provincias.

21 La Corte Suprema declaró la inconstitucionalidad del artículo 18 de la ley núm. 24,463 y estableció que la Cámara Federal de la Seguridad Social dejará de intervenir en grado de apelación contra la sentencia de los jueces federales con asiento en las provincias, que serán de competencia de las respectivas cámaras federales. En particular, en el considerando 16 se hace expresa referencia al federalismo y a la descentralización institucional, lo que consideramos un precedente de singular importancia, que debe extenderse a otras materias, tal como lo postulamos en la propuesta 14 .

22 Véanse nuestros comentarios "La Corte Suprema de Justicia, garante de la autonomía municipal. Análisis de los casos «Municipalidad de la ciudad de San Luis c. Provincia de San Luis y otro» y «Ponce Carlos Alberto c. San Luis, Provincia de»", Debates de Actualidad, Asociación Argentina de Derecho Constitucional, Buenos Aires, núm. 195, 2005, pp. 146 y 158, y "La Corte Suprema de Justicia y la reafirmación de la autonomía municipal", La Ley, Suplemento extraordinario de derecho constitucional, 75 Aniversario, agosto de 2010, y los de Ábalos, María Gabriela sobre "Autonomía municipal”, cap. XL del libro Corte Suprema de Fusticia de la Nación. Máximos precedentes. derecho constitucional, director Pablo Manili, cit., t. IV, pp. 635 y ss. 
Esta revista forma parte del acervo de la Biblioteca Jurídica Virtual del Instituto de Investigaciones Jurídicas de la UNAM

fallado el 11 de noviembre de 2014, con el voto unánime de los ministros Maqueda, Fayt, Highton de Nolasco y Lorenzetti, donde el más alto tribunal ordena a la provincia de La Rioja la sanción de una ley de coparticipación impositiva para los municipios, en cumplimiento de las Constituciones de la nación y de la provincia. Los fundamentos de la Corte son de enorme relevancia institucional y admiten una doble lectura, que alcanza también al orden federal, pues se trata de situaciones similares, con más de una quincena de años de incumplimientos constitucionales en una cuestión tan decisiva como la coparticipación impositiva. ${ }^{23}$

En particular, consideramos que debe interpretarse con criterio federal la cláusula del artículo 31 de la Constitución Nacional, que establece dicha supremacía, y que no puede confundirse con una superioridad centralista del gobierno federal sobre los provinciales, y de éstos sobre los municipales. Como lo ha sostenido caracterizada doctrina, ${ }^{24}$ "constituye un grave error de interpretación constitucional asignar a priori supremacía a una ley del Congreso sobre normas provinciales o municipales”, ya que todo depende de las competencias asignadas por la Constitución Nacional, que es la norma suprema, a la cual deben supeditarse todos los órdenes gubernamentales de nuestra Federación. En definitiva, deben invalidarse por inconstitucionales los avances sobre las competencias locales, y aquí nos referimos no sólo a los avances del gobierno federal sobre los provinciales sino también de éstos sobre los municipales. ${ }^{25}$

23 Hernández, Antonio María, "Sin coparticipación impositiva no hay federalismo", Clarín, Opinión, pp. 33, 27 de noviembre de 2014. Tuvimos el honor de representar a la municipalidad de la capital ante la Corte Suprema de Justicia de la Nación, que hizo lugar a nuestro recurso de queja contra la provincia de La Rioja, en dicho histórico fallo.

24 Véase nuestra obra Federalismo y constitucionalismo provincial, ya citada, donde consignamos las opiniones de Clodomiro Zavalía y de Arturo M. Bas al respecto (pp. 330 y notas 36 y 332 y nota 40). Asimismo, es muy clara la opinión de Alexander Hamilton en $\mathrm{El} \mathrm{Fe}$ deralista, núm. 33, quien enfatizaba que las leyes federales que no eran dictadas "conforme a la Constitución" no eran supremas, por ser una "usurpación de un poder no conferido por la Constitución” (Hamilton et al., El Federalista, México, Fondo de Cultura Económica, 2006, p. 132).

25 El problema de las competencias es el más importante de esta forma de Estado, caracterizada por la coexistencia de diversos órdenes estatales y gubernamentales. Y por ello, en los casos de conflictos, resulta tan trascendente el control de constitucionalidad de la Corte Suprema de Justicia, que debe asegurar la supremacía de la Constitución, en el estricto respeto de las competencias fijadas a cada uno de los órdenes gubernamentales, en ejercicio de sus soberanías y autonomías. Véase nuestro artículo "Soberanía y autonomía 
Esta revista forma parte del acervo de la Biblioteca Jurídica Virtual del Instituto de Investigaciones Jurídicas de la UNAM

\section{PROMOVER UN NUEVO ORDENAMIENTO TERRITORIAL} DEL PAÍS QUE MODIFIQUE LA ENORME GONCENTRACIÓN DE PODER POLÍTICO, EGONÓMICO, DEMOGRÁFICO Y GULTURAL EN EL ÁREA METROPOLITANA DE Buenos Aires

Se han confirmado los peligros y males que desde el siglo XIX señalaron entre otros Alberdi en sus Bases al oponerse a la capitalización de Buenos Aires, Sarmiento en Argirópolis y Alem en su famosa profecía del 80 en el debate sobre la federalización de la ciudad de Buenos Aires. Ya en el siglo XX, Martínez Estrada nos habló de la "cabeza de Goliath", y posteriormente Félix Luna en su libro Buenos Aires y el país, sostuvo que éste era un problema estructural no resuelto que atraviesa toda nuestra historia.

Este fenómeno notable de concentración que alcanzara todos los órdenes de la vida social argentina en relación con su capital, y que se repite en casi todas las provincias, ha sido similar al producido en otros países latinoamericanos, que desafortunadamente no han podido evitar este rasgo común a las sociedades subdesarrolladas, que presentan un inadecuado ordenamiento territorial, con marcadas asimetrías.

El proceso de centralización del país en torno a su área metropolitana de Buenos Aires, donde en menos del 1\% del territorio se asienta casi el $35 \%$ de la población, se complementa con la circunstancia de que casi el $80 \%$ de la producción argentina se origina en un radio que apenas excede los $500 \mathrm{kms}$ a partir de dicha área.

Para nosotros resulta claro que el federalismo como forma de Estado consagrada en las Constituciones nacionales de 1853 y 1860 fue una decisión correcta para solucionar los graves problemas políticos, económicos y sociales de un país tan extenso, que necesitaba de una efectiva descentralización del poder.

Pero también pudo observarse que la dificultosa vigencia de la Constitución se hizo particularmente evidente en este aspecto, ya que en la realidad se fue imponiendo un proyecto unitarizante, de centralización del poder en el gobierno, llamado federal, asentado en el puerto de Buenos Aires, que fue avanzando sobre el diseño constitucional y las

provinciales en la doctrina y jurisprudencia de la CSJN", ya citado. Asimismo, sobre la supremacía de la Constitución y la función de los jueces para defenderla, recuérdese a Alexander Hamilton, quien sostuvo: "Ningún acto legislativo contrario a la Constitución puede ser válido". El Federalista, núm. 78, cit., p. 332). 
Esta revista forma parte del acervo de la Biblioteca Jurídica Virtual del Instituto de Investigaciones Jurídicas de la UNAM

autonomías provinciales, así como tampoco se respetaban las autonomías municipales.

Este proceso negativo no pudo ser impedido ni siquiera por la reforma constitucional de 1994, que tuvo como una de sus ideas-fuerza la profundización de la descentralización del poder. Por eso, a veinte años de dicha reforma, es menester dar estricto cumplimiento a la misma y poner en funcionamiento sus instituciones, a las que nos estamos refiriendo.

\section{SANCIONAR LA LEY CONVENIO DE GOPARTICIPACIÓN IMPOSITIVA, DE GONFORMIDAD GON LOS PRINCIPIOS CONSTITUCIONALES ${ }^{26}$}

Es absolutamente impostergable sancionar la ley convenio de coparticipación, para terminar con la violación de la Constitución, que ha fijado un plazo ya largamente vencido, y porque ello es imprescindible para cambiar la deprimente realidad de nuestro federalismo. Es muy penoso advertir la casi inexistente reacción por parte de las provincias frente a tan graves circunstancias. $^{27}$

Para salir del "laberinto" actual de la coparticipación debemos seguir nuestro hilo de Ariadna, que no es otra cosa que respetar los mandatos de la ley suprema.

La masa coparticipable debe restablecerse de acuerdo con la ley suprema, para lo cual es menester derogar o modificar ostensiblemente la casi totalidad de asignaciones específicas hoy vigentes, que la han disminuido, consolidando el actual unitarismo fiscal.

Luego hay que fijar la distribución primaria y secundaria con base en los criterios constitucionales. En este sentido, resulta decisivo poner el énfasis en las modificaciones sobre las competencias, servicios y funciones

26 Para un análisis de la coparticipación impositiva, remitimos a nuestras obras Federalismo y constitucionalismo provincial, cit., pp. 69 y ss., y Cumplir el programa constitucional, Buenos Aires, Ediciones IML, 2012, cap. 3 "La coparticipación impositiva federal", pp. 11-129, entre otros aportes realizados en esta materia.

27 Algunas pocas provincias (San Luis, Santa Fe y Córdoba) han demandado a la nación ante la Corte Suprema de Justicia de la Nación, que no ha resuelto todavía la cuestión a pesar del tiempo transcurrido. Pero resulta claro que todas ellas son dependientes - en mayor o menor medida - no sólo de los fondos coparticipables, sino también de otros envíos discrecionales que puede efectuar el gobierno nacional. 
Esta revista forma parte del acervo de la Biblioteca Jurídica Virtual del Instituto de Investigaciones Jurídicas de la UNAM

entre la nación, las provincias y la ciudad de Buenos Aires, ya que estos últimos niveles gubernamentales, además de los municipios, son los que tienen mayores responsabilidades al respecto. ${ }^{28}$

Un mayor reconocimiento de la participación de las provincias y la ciudad de Buenos Aires - que necesariamente debe repercutir después en la coparticipación a los municipios-, hará relativamente más sencilla la discusión posterior sobre la distribución secundaria, donde se advierten las disputas entre las provincias más grandes y desarrolladas y las más pequeñas y menos desarrolladas. ${ }^{29}$

En este aspecto, lo que he denominado el "triunfo del proyecto centralista" ha dado como resultado un país de enormes diferencias y desequilibrios, según los índices de desarrollo humano, de producto bruto o de ingreso per cápita, que es menester modificar. Los criterios de solidaridad exigidos por la Constitución deben respetarse, como lo hacen otras federaciones, como la canadiense, la australiana o la alemana, que son notables ejemplos en esta materia. ${ }^{30}$

28 Piénsese en educación, salud y seguridad, principalmente a cargo de las provincias, con los enormes gastos en personal requeridos, además de los otros servicios - como los judiciales - y de los correspondientes a los gobiernos locales.

29 Es esencial que en cumplimiento de los criterios constitucionales, en la distribución primaria exista una porción mayor de la masa coparticipable para el conjunto de los gobiernos subnacionales, como se había alcanzado con la Ley 23,548. Ello significa que debe retroceder el gobierno nacional en su participación, que hoy alcanza cifras propias del unitarismo fiscal que vivimos. Frente a los que suponen que ello es imposible, recordamos que durante las presidencias de Frondizi y de Alfonsín, con vigencia de la democracia, el Congreso sancionó las leyes 14,788 y 23,548, respectivamente, que así lo dispusieron. (Cffr. Hernández, Antonio María, Federalismo y constitucionalismo provincial, cit., pp. 69 y ss.).

30 Resulta muy ilustrativo analizar el caso de la federación canadiense, donde las provincias "pobres" (Nova Scotia, New Brunswick, P.E.I. y Newfoundland) reciben más fondos del gobierno federal que las provincias "ricas" (British Columbia, Alberta, Saskatchewan, Manitoba, Ontario y Québec, en aplicación de un sistema de igualación ("equalization system"), que es un programa puramente federal. Asimismo, existen distintos impuestos en las provincias, además de producirse una clara transferencia de recursos de las provincias más ricas: Alberta y Ontario, a las restantes. Véase al respecto el trabajo de Michael Butler, titulado Federal-Provincial Fiscal relations in Canada, preparado para el Forum of Federations, en el Seminario Internacional sobre Federalismo, realizado en Pilar, provincia de Buenos Aires, los días 2 y 3 de octubre de 2003, con la participación del Programa de Naciones Unidas para el Desarrollo y el gobierno de la provincia de Buenos Aires. Véase también la conocida obra de Ronald L. Watts, The Spending Power in Federal Systems: a Comparative Study, Ontario, Canada, Institute of Intergovernmental Relations, Queen's University, Kingston, 1999.

D. R. C 2016. UNAM, Instituto de Investigaciones Jurídicas, Boletín Mexicano de Derecho Comparado, núm. 146, pp. 375-418. 
Esta revista forma parte del acervo de la Biblioteca Jurídica Virtual del Instituto de Investigaciones Jurídicas de la UNAM

No obstante la claridad y altura de los objetivos perseguidos por el Constituyente, se han difundido en estos años algunas propuestas que no sólo desconocían la letra y espíritu de la ley suprema en esta materia, sino que pretendían volver lisa y llanamente al sistema anterior, de completa separación de fuentes, con el indisimulable propósito de ahondar las diferencias existentes entre las provincias y centralizar aún más el país. ${ }^{31}$

Por todo ello, debe comenzar ahora mismo este debate complejo y decisivo, según las bases constitucionales establecidas. ${ }^{32}$ Para ello es impres-

31 En definitiva, el objetivo de estos sectores ha sido el de impedir que efectivamente se cumpla con el mandato constitucional que establece la coparticipación. Incluso se ha llegado a sostener desde una visión economicista que existen provincias y municipios inviables. Como otra de las paradojas argentinas, mientras el mundo desarrollado avanza en la descentralización, en nuestro país hay sectores de enorme poder político y económico que persiguen lo contrario, pese al mandato constitucional. Se trata del "conservadurismo unitario", que quiere mantener el statu quo del centralismo, en la ajustada caracterización de Juan J. Llach en su obra Federales y unitarios en el siglo XXI, Buenos Aires, Temas, 2013, cap. V "El federalismo, clave del desarrollo político y humano". Por eso es tan trascendente el fallo de la Corte Suprema de Justicia de la Nación en el caso "Intendente Municipal Capital", antes comentado, donde se manifiesta que es notoriamente irrazonable aducir dificultades para el logro de los acuerdos de coparticipación, cuando se trata de una demora de dieciséis años, como en el caso de la provincia de La Rioja. Piénsese que en el caso federal, hemos superado los dieciocho años de violación constitucional.

32 Para contribuir a este demorado y fundamental debate, el Instituto de Federalismo de la Academia Nacional de Derecho y Ciencias Sociales de Córdoba, que dirijo, ha publicado el libro que también dirigiera sobre Aspectos económicos y financieros del federalismo argentino, en 2008, con los aportes de economistas, juristas y de otras disciplinas, pues tuvo la coautoría del suscrito, Frías, Dalla Vía, Garat, Barrera Buteler, Heredia, Asensio, Rezk, Midón, Martínez, Palazzo, Prieto, Frediani, Roccatagliata y Della Paolera. Asimismo, debe destacarse el esfuerzo interdisciplinario que estamos realizando distintas instituciones para profundizar el estudio del federalismo fiscal, como lo indica la obra Consecuencias económicas y políticas del federalismo fiscal argentino, editada por Carlos Gervasoni y Alberto Porto, con la coautoría de Abraham, Bonvecchi, Capello, Cont, Días Frers, Figueras, Freille, Gervasoni, Grotz, Hernández, Juarros, Llach, Morcarz, Porto y Rezk (Económica, Revista de la Facultad de Ciencias Económicas de la Universidad Nacional de La Plata), resultado del 16o. Seminario de Federalismo Fiscal realizado en La Plata, en 2013 y que se continúa con este 17o., en Córdoba. Asimismo, recientemente Juan José Llach publicó su libro Federales y unitarios en el siglo $X X I$, ya citado, donde también formula su propuesta al respecto. Estamos convencidos de que con los aportes ya producidos por los centros especializados en federalismo fiscal de La Plata, Córdoba, Santa Fe y Buenos Aires, con distinguidos autores, como Porto, Piffano, Rezk, Capello, Asensio y Llach — aquí presentes - no será difícil alcanzar las soluciones técnicas económicas requeridas. El problema es esencialmente político, y por ello es penoso advertir la grave responsabilidad que han tenido y tienen en este aspecto la presidencia y los gobernadores, pues son los primeros que deben avanzar en los acuerdos para la san- 
Esta revista forma parte del acervo de la Biblioteca Jurídica Virtual del Instituto de Investigaciones Jurídicas de la UNAM

cindible el ejercicio de una verdadera política arquitectónica que supere antagonismos partidarios, termine el hiperpresidencialismo, fortalezca relaciones interjurisdiccionales y posibilite un desarrollo equilibrado del país conforme al proyecto federal de la ley suprema.

Por otra parte, es igualmente urgente que similares criterios sean utilizados para el respeto y fortalecimiento de las facultades tributarias provinciales y municipales, además de los sistemas de coparticipación provinciales a sus gobiernos locales. ${ }^{33}$

\section{RESPETAR LOS PRINCIPIOS FEDERALES EN LA SANGIÓN}

ANUAL DE LOS PRESUPUESTOS

No se cumple el mandato del inciso 8 del artículo 75 de la Constitución Nacional, que establece que el presupuesto general de gastos de la nación debe fijarse anualmente "conforme a las pautas establecidas en el tercer párrafo del inciso 2 de este artículo", o sea, las referidas a la Ley de Coparticipación Impositiva, en cuanto a "objetividad, equidad y solidaridad". Además, hay que resaltar que el inciso 8 dice que el presupuesto general de gastos y cálculo de recursos debe efectuarse "en base al programa general de gobierno y al plan de inversiones públicas", lo que para nosotros implica una definición constitucional que relaciona a la importante ley con la planificación, pues no se puede dar otro sentido a las palabras "programa" y "plan" que utiliza la ley suprema. A su vez, el presupuesto es considerado por la doctrina clásica

ción de las leyes de coparticipación impositiva, entre otros arreglos interjurisdiccionales, tal como lo plantea la ley suprema.

33 Remitimos a nuestros artículos "Unitarismo fiscal, coparticipación impositiva y violación de la Constitución", La Voz del Interior, Córdoba, 23 de agosto de 2012, y "Nuevas reflexiones sobre unitarismo fiscal, coparticipación impositiva y violación de la Constitución", La Voz del Interior, Córdoba, 29 de noviembre de 2012. En el segundo artículo ponemos de relieve cómo en nuestra provincia se utiliza el mismo criterio centralista del orden federal, ya que los municipios son privados de enorme cantidad de recursos, con el mismo artilugio de los fondos de asignación específica que son detraídos de la masa coparticipable. Para un análisis más detenido de los poderes tributarios locales, véase nuestra obra Derecho municipal, 2a. ed., Depalma, 1997. Y en cuanto a diversas propuestas para fortalecer los poderes tributarios provinciales, véanse los trabajos de Juan Llach en su obra indicada y de Horacio Piffano y Lucio Castro, titulados "Opciones tributarias de los gobiernos subnacionales en el actual escenario federal" y "Desafíos y potencial del impuesto inmobiliario en la Argentina", que fueran presentados en el 17o. Seminario Fiscal de Córdoba. 
Esta revista forma parte del acervo de la Biblioteca Jurídica Virtual del Instituto de Investigaciones Jurídicas de la UNAM

del derecho financiero como un instrumento de gobierno, de administración y de planificación.

En consecuencia, tanto para el gasto público como para el cálculo de recursos previstos por el presupuesto, debe existir como base un programa de gobierno y de inversiones públicas que también respete las pautas constitucionales.

Este inciso que comentamos contiene una política constitucional, que vincula al presupuesto con temas esenciales del proyecto federal: la regionalización, la integración, la descentralización y el fortalecimiento de las autonomías provinciales, de la Ciudad de Buenos Aires y municipales.

En consecuencia, al violarse sistemáticamente este mandato de la ley suprema - lo que se repite cada año-, se agudiza la situación actual de asfixiante centralización que impide un desarrollo armónico del país. ${ }^{34}$

Esta cuestión es de enorme trascendencia para nuestro federalismo. Para ejemplificarlo, veamos estos datos que exhiben en toda su dimensión lo que ocurre con el destino del gasto público en nuestro país, con base en el estudio presentado por el licenciado Juan José Llach titulado "Una década sin federalismo y sus consecuencias", ${ }^{35}$ que así resumimos: ${ }^{36}$

En el punto que califica como "el toma todo", ha destacado que mientras en 1998 los impuestos no coparticipados por el gobierno federal a provincias y municipios alcanzaba al 5,4\% del total, en 2011 dicho porcentaje alcanzó el $23,6 \%$ y que ello ha significado que los gobiernos subnacionales pudieran haber recaudado 12.065 millones de dólares más durante el año 2011, si se hubiese mantenido el porcentaje de 1998. Asimismo sostiene que entre los años 2004 y 2011 las provincias y municipios dejaron de percibir 67,000 millones de dólares por esta causa. Y en el punto "el gran recaudador" indica que mientras que en el año 1998 el Gobierno Federal recaudaba el 80,1\% del

34 Véase el artículo "Sin respeto por el federalismo", que publicáramos en el diario La Nación de la ciudad de Buenos Aires el 18 de diciembre de 2006. Asimismo, es muy interesante el análisis de Juan Llach, titulado "Anatomía de un despilfarro", publicado en el diario La Nación del 23 de julio de 2009, que precisa la mayoría del destino de los fondos públicos para subsidios y exenciones impositivas, que además beneficiaron al área metropolitana de Buenos Aires, en desmedro del interior del país y en evidente violación de las normas constitucionales.

35 En el Congreso de Aapresid, celebrado en Rosario, el 10 de agosto de 2012.

36 Hernández, Antonio María, "Informe del federalismo argentino 201 1”, en el Cuaderno de Federalismo núm. XXV, editado por el Instituto de Federalismo de la Academia Nacional de Derecho y Ciencias Sociales de Córdoba, Córdoba, 2012, pp. 16 y 17. 
Esta revista forma parte del acervo de la Biblioteca Jurídica Virtual del Instituto de Investigaciones Jurídicas de la UNAM

total de recursos públicos nacionales, las Provincias el 18,1\% y los Municipios el 1,8\%, en el año 2011 la Nación ha recaudado el 84,4\%, las Provincias el $14,2 \%$ y los Municipios sólo el 1,4\%, en un proceso que inocultablemente indica el unitarismo fiscal que estamos soportando. Y en el punto "yo gaste, que otro recaude (dicen provincias y municipios)", Llach dice que aunque los gobiernos subnacionales sólo recaudaron el 15,6\% en el año 2011, sin embargo gastaron el 44,4\% del gasto público total, lo que exhibe una muy escasa correspondencia fiscal, en el marco del federalismo fiscal comparado. También el autor indica en el punto "el gran gastador", que el gobierno central ha aumentado notoriamente su participación en el gasto público de un 52,9\% en 2003 a un 55,6\% en 2011, mientras que las provincias decrecieron de un $39,3 \%$ a un $37,2 \%$ en esos años y los municipios de un $7,8 \%$ a un $7,2 \%$. Asimismo el destacado economista expuso que las apropiaciones indebidas efectuadas por la Nación entre el 2003 y el 2011 produjeron estas consecuencias en las provincias y municipios: a) menor coparticipación impositiva, como antes lo vimos; b) menor capacidad de gasto, ya que sólo en el año 2011 estos gobiernos subnacionales dejaron de gastar la suma de 5.707 millones de dólares; y c) menor capacidad de decisión, por el aumento de las transferencias discrecionales, que en el año 2011 alcanzaron a 8.487 millones de dólares en 2011 y a 43.342 millones de dólares entre 2004 y 2011.

Asimismo, queremos completar este análisis sobre la arbitrariedad en el destino del gasto público federal, con estos datos presentados por el IERAL de la Fundación Mediterránea en el trabajo "Los diferentes tratamientos fiscales regionales en el proyecto de presupuesto 201 1", que así resumimos: ${ }^{37}$

...nuevamente se destaca la manifiesta desigualdad en el destino del gasto público, de acuerdo al reparto de las transferencias nacionales a las jurisdicciones provinciales, según el proyecto de presupuesto mencionado. En pesos por cápita o persona y por gasto primario nacional y por coparticipación y leyes especiales, se observa en las jurisdicciones: Ciudad Autónoma de Buenos Aires, 38.726 pesos; Santa Cruz, 22.163 pesos; Tierra del Fuego, 18.814 pesos; La Pampa, 14.778 pesos; La Rioja, 14.708 pesos; Catamarca, 14.091 pesos; Río Negro, 13.108 pesos, Formosa, 13.101 pesos; Chubut, 11.908 pesos; San Juan, 11.577 pesos; Santiago del Estero, 11.303 pesos; San Luis, 10.840

37 Hernández, Antonio María, "Informe del federalismo argentino 2010", en el Cuaderno de Federalismo, núm. XXIV, editado por el Instituto de Federalismo de la Academia Nacional de Derecho y Ciencias Sociales de Córdoba, Córdoba, 2011, pp. 18 y 19. 
Esta revista forma parte del acervo de la Biblioteca Jurídica Virtual del Instituto de Investigaciones Jurídicas de la UNAM

pesos; Chaco, 10.673 pesos; Jujuy, 10.145 pesos; Entre Ríos, 9.838 pesos; Tucumán, 9.183 pesos; Corrientes, 9.120 pesos; Neuquén, 8.795 pesos; Santa Fe, 8.457 pesos; Salta, 8.371 pesos; Mendoza, 8.124 pesos; Córdoba, 8.109 pesos; Misiones, 7.704 pesos y Buenos Aires, 6.596 pesos. O sea que la desigualdad es manifiesta, ya que la mayor cantidad de gastos públicos federales se efectúa por parte, en la Ciudad Autónoma de Buenos Aires, que es la más rica del país, donde confluyen los pagos inconstitucionales de la justicia civil, penal, comercial y laboral (antes nacional), además de la Policía Federal y los subsidios al transporte, gas y electricidad y entre las provincias, también por las provincias de Santa Cruz y Tierra del Fuego, que distan mucho de ser las provincias con mayor pobreza.

Ante esta realidad deprimente e incontrastable, no cabe dudar que si el Congreso asume como corresponde el ejercicio de sus competencias constitucionales en torno al presupuesto ${ }^{38}$ - denominado la ley de las leyes - y aplica estrictamente el criterio federal de la ley suprema para fijar el destino del gasto público en cada ejercicio anual, seguramente el proceso de cambio hacia una democracia republicana y federal será más rápido de lo que imaginamos.

\section{Federalizar el Banco Central}

Otra importante reforma efectuada por la Convención Nacional Constituyente de 1994 fue la del inciso 6 del artículo 75, al prescribirse que corresponde al Congreso "establecer y reglamentar un banco federal con facultad de emitir moneda...". Al fundamentar la reforma, los convencionales Maqueda, Díaz Araujo, Berhongaray y Masnatta explicitaron el objetivo de la misma, que fue y es adecuar el actual Banco Central en su denominación y concepción, al de un Estado federal, citando como ejemplos las instituciones similares de Estados Unidos, Suiza y Alemania. Se han formulado ya propuestas doctrinarias y legislativas, que deben impulsarse, ${ }^{39}$ ya que recientemente se perdió la oportunidad para ello. ${ }^{40}$

38 Lo que implica la derogación inmediata del artículo 37 de la Ley de Administración Financiera, que dispone que por decretos del Poder Ejecutivo se pueden modificar las partidas presupuestarias, con lo cual quedan desconocidas las atribuciones del Congreso.

39 Véase en nuestra obra citada Federalismo y constitucionalismo provincial, p. 84, nota. 101, la enunciación de los trabajos de Ramón Frediani y la referencia a los proyectos legisla- 
Esta revista forma parte del acervo de la Biblioteca Jurídica Virtual del Instituto de Investigaciones Jurídicas de la UNAM

No cabe dudar sobre la trascendencia que tendrá la participación provincial en la política bancaria, cambiaria y monetaria, que incidirá en los aspectos económicos del federalismo argentino, tal como lo previó el constituyente. No se puede continuar con esta estructura actual, propia de un Estado unitario, que soslaya las realidades regionales y provinciales y profundiza el centralismo, muestra evidente de nuestro subdesarrollo y decadencia.

\section{AFIANZAR El FEDERALISMO DE COORDINACIÓN O CONGERTAGión MEDIANTE UN MEJOR EJERCICIO DE RELACIONES INTERJURISDICGIONALES. CREACIÓN DE UNA ASOCIACIÓN o Gonferencia Nacional de Gobernadores}

Otro de los grandes avances de la reforma constitucional de 1994 fue la plena incorporación del federalismo de coordinación o concertación. ${ }^{41}$ Ejemplos de ello son las leyes-convenio de coparticipación impositiva (artículo 75, inciso 2), el organismo fiscal federal (artículo, 75 inciso 2), la participación provincial en los entes reguladores y de control de los servicios públicos de competencia nacional (artículo 42), la creación de regiones (artículo 124), la celebración de convenios internacionales (artículo 124), e incluso la integración supranacional (artículo 75, inciso 24).

Por otra parte, se ha avanzado desde hace décadas en la celebración de tratados interprovinciales y en la creación de consejos federales en diversas materias.

tivos de reforma presentados en 1995 en la Cámara de Diputados de la Nación por los diputados Enrique Olivera y el suscrito. Asimismo, en el libro de Aspectos fiscales y económicos del federalismo argentino, editado por el Instituto de Federalismo, ya citado, se encuentran los trabajos respectivos de Eugenio Palazzo y de Ramón Frediani al respecto. A ellos deben sumarse los aportes del distinguido economista Julio Olivera.

40 Con la sanción de la Ley núm. 26.739, efectuada en 2012, que no modificó la estructura centralista, en violación de la normativa constitucional y como otra muestra más de la anomia que padecemos.

41 Para la distinción entre el federalismo "dual o competitivo" y el federalismo "de coordinación o concertación", véase nuestra obra Federalismo y constitucionalismo provincial, ya citada, cap. I "Sistemas políticos federales", en el punto "Clasificación de los sistemas políticos federales", pp. 17 y 18. Pedro J. Frías, que prefería denominarlo "de concertación”, fue precursor de esta incorporación tanto a la Constitución Federal como a las Constituciones provinciales. 
Esta revista forma parte del acervo de la Biblioteca Jurídica Virtual del Instituto de Investigaciones Jurídicas de la UNAM

Pero es evidente que no existen relaciones interjurisdiccionales modernas y maduras entre los diversos órdenes gubernamentales ni se ha observado una efectiva y plena vigencia del federalismo de coordinación o concertación.

No desconocemos que este proceso demanda una elevación de nuestra cultura política, para poder superar al individualismo exacerbado, las tendencias corporativas y la imposibilidad — que muchas veces padecimos - de proyectar y ejecutar políticas arquitectónicas frente a los problemas estructurales de la sociedad y el Estado argentinos.

Ya veremos en esta propuesta y en otras sucesivas, que el federalismo de coordinación o concertación es una herramienta fundamental para el desarrollo equilibrado e integrado del país, a través de sus múltiples aplicaciones.

Aunque en los puntos siguientes seguiremos tratando este tema, en esta oportunidad planteamos la creación de una Asociación o Conferencia Nacional de Gobernadores, como existen en las federaciones norteamericana y mexicana, a los fines de mejorar estas relaciones interjurisdiccionales.

Por otra parte, tal vez sólo así podrá existir un mayor equilibrio en el diálogo entre el presidente y los gobernadores, que permita el cumplimiento del proyecto federal de la Constitución Nacional.

\section{REALIZAR UNA PLANIFICACIÓN FEDERAL PARA EL DESARROLLO DEL PAÍS, GON PARTICIPACIÓN DE LOS DISTINTOS NIVELES ESTADUALES}

La decadencia argentina está ligada - entre otras causas - a la incapacidad de pensar el futuro y de acordar políticas de Estado. Sólo se piensa en la coyuntura, y por ello no se resuelven los grandes problemas nacionales. Bien se ha dicho que los políticos en serio son los que piensan en las próximas generaciones, en lugar de las próximas elecciones. Se ejercita hasta el extremo la dimensión agonal de la política, cuando lo que realmente puede transformar al país es la dimensión arquitectónica. Y así como en virtud de esta última se pudo acordar un texto constitucional en 1994, que significara un enorme avance en esta materia, aunque luego caímos en la anomia que nos caracteriza, ahora debemos hacer el esfuerzo de planificar de manera federal nuestro desarrollo futuro. Ello significa la 
Esta revista forma parte del acervo de la Biblioteca Jurídica Virtual del Instituto de Investigaciones Jurídicas de la UNAM

participación de todos los órdenes gubernamentales para hacer realidad los principios de la república federal. Este es el gran desafío que tenemos por delante. ${ }^{42}$

\section{PROMOVER LAS REGIONES PARA EL DESARROLLO ECONÓMICO Y SOCIAL}

También aquí se advierte la importancia del cumplimiento del artículo 124 de la Constitución Nacional, que prevé las regiones como instituciones esenciales para el desarrollo económico y social y la integración nacional.

Estimamos que aunque el mapa regional se encuentra casi diseñado con las regiones ya constituidas del gran norte argentino, Patagonia, Nuevo Cuyo y Centro - faltando sólo la integración de la Provincia de Buenos Aires y de la Ciudad Autónoma-, no se aprecia un avance de dicho proceso. Las graves situaciones institucionales, económicas y sociales atravesadas, sumadas a la ausencia de una política arquitectónica, seguramente han influido en ello. Sólo se ha advertido en los últimos años una cierta actividad destacable en la región centro.

Necesitamos imperiosamente modificar la forma de embudo de nuestro ordenamiento territorial, mediante el fortalecimiento de nuestras regiones y provincias, desalentando los procesos de migración interna, que

42 Véase el reciente libro de Juan J. Llach, Federales y unitarios en el siglo XXI, ya citado, cuyo cap. V tiene como título "El federalismo, clave del desarrollo político y humano". Se trata de una propuesta de gran calidad e importancia, para conducir a la Argentina a la senda del desarrollo, en un mundo que ofrece desafíos y sobre la base de cumplir el proyecto federal. Para ello, Llach propone planes de desarrollo con base en grandes acuerdos políticos, que permitan solucionar lo que denomina nudos gordianos y bajos continuos de nuestra preocupante realidad. Entre los primeros menciona la cuestión federal; la pobreza y la distribución del ingreso; la educación, ciencia y tecnología y el desarrollo integrado y sostenible y la inserción externa. Y con estos bajos continuos: un inadecuado funcionamiento de las instituciones políticas, una fuerte puja distributiva entre sectores y una imprecisa definición de los roles del Estado y del mercado. Por eso, el autor enfatiza en la necesidad de un cumplimiento estricto de la Constitución nacional en sus aspectos republicanos y federales, para superar la realidad signada por la anomia, el hiperpresidencialismo y el centralismo. Y aboga por un fortalecimiento de los poderes tributarios provinciales y municipales y por un nuevo sistema de coparticipación impositivo y de federalismo fiscal, con respeto de la Constitución y de criterios técnicos y federales. Sostiene que esta propuesta federal es una tarea ciclópea, tendiente a modificar el statu quo actual, defendido por el "conservadurismo unitario". 
Esta revista forma parte del acervo de la Biblioteca Jurídica Virtual del Instituto de Investigaciones Jurídicas de la UNAM

tanto nos han perjudicado, a la luz de los desequilibrios y desarmonías que se advierten en nuestra realidad.

Y avanzar en proyectos estratégicos como los de los corredores bioceánicos, como más adelante consideraremos en la propuesta 19.

\section{IMPULSAR EL NUEVO ROL DE REGIONES, PROVINCIAS Y MUNICIPIOS EN LOS PROCESOS DE INTEGRACIÓN NACIONAL Y SUPRANACIONAL ${ }^{43}$}

Para nosotros, la integración, junto a la descentralización, constituyen una respuesta inteligente a los desafios de la globalización. El neologismo "glocal" nos indica que debemos pensar ubicados en el mundo globalizado en que estamos insertos, pero que debemos actuar localmente, y, en consecuencia, existe la urgente necesidad de defender las autonomías y competencias de los gobiernos subnacionales y locales. La importancia de las ciudades en el mundo globalizado ha sido estudiada por Jordi Borja y Manuel Castells. ${ }^{44}$ En consecuencia, estos dos procesos interrelacionados (integración y descentralización) requieren un profundo cambio del derecho público, a la luz del mundo actual, que muestra la tendencia hacia un regionalismo abierto, más allá de las fronteras nacionales.

En nuestro país se está avanzando en el desarrollo de estos roles de los gobiernos subnacionales, luego de la reforma del artículo 124 de la Constitución Nacional - también producido por Convención Nacional Constituyente de 1994-, que ha admitido la celebración de convenios internacionales por parte de las provincias. ${ }^{45}$

43 Hemos desarrollado el rol de las regiones, provincias y municipios en los procesos de integración nacional y supranacional en nuestras obras Integración y globalización: rol de las regiones, provincias y municipios, con prólogo de Eduardo García de Enterría, Buenos Aires, Depalma, 2000, y Federalismo y constitucionalismo provincial, Buenos Aires, Abeledo-Perrot, 2009.

44 En su obra Local y global. La gestión de las ciudades en la era de la información, Madrid, Taurus, 1997.

45 Véase el libro El rol de los gobiernos subnacionales en los procesos de integración regional. Reflexiones sobre el caso del Foro Consultivo de Municipalidades, Estados, Provincias y Departamentos del Mercosur, editado por el Cari (Consejo Argentino para las Relaciones Internacionales) y Cebri (Centro Brasileiro de Relações Internacionais), con la dirección del proyecto a cargo del embajador Eduardo Iglesias y la coordinación académica a cargo de Claudia Gasol Varela, Buenos Aires, 2010. Asimismo, el Cari, con la dirección antes mencionada, 
Esta revista forma parte del acervo de la Biblioteca Jurídica Virtual del Instituto de Investigaciones Jurídicas de la UNAM

\section{FortaleGer las aUtonomías PROVInciales, DE LA CiUdAD Autónoma de Buenos Aires y de los Muniaipios}

El federalismo, como forma de Estado, se asienta en la coexistencia de distintos órganos gubernamentales, con base en el principio de la lealtad federal y del respeto de la unión y de la diversidad. Y por ello es tan trascendente la afirmación de las autonomías de las provincias, de la Ciudad de Buenos Aires y de los municipios, como expresión indudable de la descentralización del poder. De ahí que sea el problema más importante de esta forma de Estado, la distribución de las competencias y el respeto de las mismas.

En un trabajo anterior nos referimos al agudo proceso de centralización que ha sufrido el país. ${ }^{46}$ Esto es lo que hay que revertir, y el difícil camino a recorrer no es otro que el prescrito por la Constitución Nacional, especialmente a la luz de la gran reforma constitucional de 1994, que tuvo como uno de sus objetivos la profundización de la descentralización del poder.

Hemos sostenido que esta cuestión fue objeto de trascendentes debates en cuatro comisiones de la Convención Nacional Constituyente, que abarcaron tres grandes capítulos: el específico de federalismo, el de la autonomía plena de la Ciudad de Buenos Aires y el reconocimiento del principio de la autonomía municipal. ${ }^{47}$

En consecuencia, deben respetarse los distintos aspectos de las autonomías: institucional, política, administrativa, financiera y económica, correspondientes a cada uno de los niveles estaduales y gubernamentales integrantes de la Federación argentina.

mantiene un registro de los convenios internacionales celebrados por nuestras provincias y la Ciudad Autónoma de Buenos Aires.

46 "La realidad de nuestro federalismo, el incumplimiento de la Constitución Nacional y la tendencia a la centralización", Consecuencias económicas y políticas del federalismo argentino, cit., pp. 17 y ss. Asimismo, véase Gelli, María Angélica, "El federalismo en emergencia y su necesaria reconstrucción” (pp. 9 y ss.), en el libro Aspectos juridicos e institucionales del federalismo argentino, director Antonio María Hernández, Instituto de Federalismo de la Academia Nacional de Derecho y Ciencias Sociales de Córdoba, 2010.

47 Para el análisis detenido de estas cuestiones, en la que no nos podemos detener por razones de brevedad, nos remitimos a nuestras obras Federalismo, autonomía municipal y Ciudad Autónoma de Buenos Aires en la reforma constitucional de 1994, Buenos Aires, Depalma, 1997; Derecho municipal, 2a. ed., Buenos Aires, Depalma, 1997, y Federalismo y constitucionalismo provincial, Buenos Aires, Abeledo-Perrot, 2009. 
Esta revista forma parte del acervo de la Biblioteca Jurídica Virtual del Instituto de Investigaciones Jurídicas de la UNAM

Por razones de brevedad, no podemos detenernos en este análisis, para lo cual nos remitimos a la bibliografía especializada. ${ }^{48}$

\section{MODIFICAR O DEROGAR LA LEGISLAGIÓN GENTRALISTA VIGENTE Y LAS POLÍTICAS RESPEGTIVAS}

Son muy amplias las reformas a producir en este aspecto, por lo que en modo alguno resulta taxativa la enunciación que efectuamos seguidamente. Esta tarea requiere de un análisis detenido de la normativa dictada, que a lo largo del tiempo fue centralizando notablemente a nuestro federalismo. Para ejemplificar esta propuesta, señalaremos algunos temas de gran relevancia, que se suman a lo indicado en otras efectuadas con anterioridad.

Y comenzamos con lo antes expuesto en torno a la imperiosa necesidad de modificar o derogar la mayoría de los tributos con asignación específica que detraen fondos de la masa coparticipable, lesionando las autonomías provinciales y municipales. ${ }^{49}$

Asimismo, a lo largo del tiempo con base en la "cláusula del progreso" del actual artículo 75, inciso 18 (antes artículo 67, inciso 16) y a la posibilidad del otorgamiento de concesiones temporales de privilegios y recompensas de estímulo por el Congreso, se fue desconociendo y afectando el

48 Véanse nuestras obras ya citadas Federalismo, autonomía municipal y ciudad de Buenos Aires en la reforma constitucional de 1994, Derecho municipal y Federalismo y constitucionalismo provincial. Para explicar la importancia de estos temas y las lesiones a las autonomías, sólo daremos algunos ejemplos: a) el enorme despojo efectuado por el gobierno federal a las provincias y municipalidades, al no sancionarse las leyes de coparticipación impositiva y al detraerse los fondos pertinentes de la masa coparticipable mediante las asignaciones específicas; b) el pago por el tesoro federal de 550 jueces de la Ciudad Autónoma de Buenos Aires, que eran nacionales y que debieran corresponder a dicha nueva jurisdicción, según lo dispuesto por el artículo 129 de la Constitución Nacional, lo que ha sido desconocido por la inconstitucional Ley 24.488 , y c) la inexistencia de ley de coparticipación impositiva para los municipios de la provincia de La Rioja, como expresión notable de las violaciones a la autonomía municipal, lo que motivara un amparo por parte de la municipalidad de la capital — que defendemos—y que ahora está a resolución de la Corte Suprema de Justicia de la Nación.

$49 \mathrm{Al}$ analizar la coparticipación impositiva federal, en nuestras obras citadas, indicamos distintas normas - pactos fiscales, leyes y decretos-, que invirtieron la primacía que habían alcanzado en la distribución primaria los gobiernos locales frente al federal, de acuerdo con la Ley 23,548, hasta llegar a la situación actual de centralismo fiscal, donde casi el $80 \%$ de los recursos son percibidos por el gobierno nacional. 
Esta revista forma parte del acervo de la Biblioteca Jurídica Virtual del Instituto de Investigaciones Jurídicas de la UNAM

poder tributario de provincias y municipios en múltiples casos: ferrocarriles, transportes, comunicaciones, minería, etcétera. En consecuencia, hay que revisar dicha legislación y políticas centralistas - casi siempre avaladas por la jurisprudencia de nuestra Corte Suprema de Justicia-, ${ }^{50}$ a la luz de la nueva normativa del artículo 75, inciso 30, de la Constitución Nacional, que ha reconocido el poder de policía y de imposición de provincias y municipios en los establecimientos de utilidad nacional, como otro hito notable de afirmación federalista, también incorporado en la reforma de $1994 .{ }^{51}$ Esto significa que debieran producirse las reformas legislativas y jurisprudenciales, a los fines del estricto cumplimiento de la ley suprema, que ha fortalecido a las autonomías provinciales y municipales en todos sus aspectos, incluyendo los tributarios y económicos.

Lo propio debe ocurrir con los subsidios, en materia de servicios públicos de transporte y energía, que están destinados mayoritariamente al área metropolitana de Buenos Aires, con una enorme desigualdad para los habitantes del interior del país.

Por otra parte, debe modificarse la Ley 24.588 por ser inconstitucional en sus artículos 2o., 7o., 8o., y 10 al violar el artículo 129 de la ley suprema y restringir la autonomía plena de la Ciudad Autónoma de Buenos Aires. Además de ello, también se afecta el federalismo, por otra razón: los anteriores jueces "nacionales" y gran parte de la Policía Federal que allí presta servicios son sostenidos por el presupuesto de la nación, en lugar del de la Ciudad Autónoma.

Asimismo, reiteramos que es imperioso terminar con el hiperpresidencialismo, que lesiona profundamente la república federal, comenzando por la inmediata derogación de los superpoderes otorgados en el artículo 37 de la Ley de Administración Financiera y de la legislación de emergencia económica, además de la modificación de la Ley 26,122 de decretos de necesidad y urgencia, que de manera inconstitucional reglamenta el artículo 99, inciso 3, de la ley suprema.

50 Tratado de derecho y economía, 3 ts., director Juan Vicente Sola, Buenos Aires, La Ley, 2013, "La cláusula del progreso", en el t. II, cap. XXII, pp. 420 y ss. y "La cláusula del progreso" (con especial referencia a los ferrocarriles)", de Alberto Bianchi, ponencia presentada en el XX Congreso de Asociación Argentina de Derecho Constitucional, en Mendoza, 2011, puntos 2, c) Los problemas del equilibrio federal, y 3 a) iii) Jurisprudencia, en especial sobre conflictos impositivos.

51 Véanse nuestras obras citadas en la nota 48, donde consideramos este punto. 
Esta revista forma parte del acervo de la Biblioteca Jurídica Virtual del Instituto de Investigaciones Jurídicas de la UNAM

En cuanto a los recursos naturales - sin perjuicio de que volvemos sobre el tema más adelante- - es evidente que debe adecuarse la legislación vigente sobre hidrocarburos, pesca y otros recursos, a lo dispuesto en el artículo 124 de la Constitución Nacional, que ha reconocido la propiedad provincial sobre los mismos. Refiriéndonos al caso de los hidrocarburos, muchos años después de la reforma, mediante la Ley 26,197, se reconocieron las competencias provinciales, al modificarse el artículo lo. de la Ley de Hidrocarburos 17,319, que las otorgaba al gobierno federal. Esa llamada "ley corta", trasuntó un espíritu federalista impuesto por la Constitución, que ha sido gravemente desconocido por la denominada Ley de Soberanía Hidrocarburíferas 26,741 de 2012, y su decreto reglamentario 1277 de dicho año. Para nosotros, hay claras objeciones sobre la constitucionalidad de estas últimas normas, que además otorgan un enorme cúmulo de atribuciones al Poder Ejecutivo, sin la adecuada participación del Consejo Federal de Hidrocarburos. ${ }^{52}$ Esto también alcanza a la reciente Ley 27,007, que ha introducido modificaciones en las anteriores leyes 17,319 y 26,741, con el mismo objetivo de profundizar un proceso de centralización en la materia, con base en un acuerdo logrado con los gobernadores de las provincias productoras, que se caracterizó por su sigilo, velocidad y uso de las viejas prácticas unitarizantes del gobierno nacional. Aquí se impone una revisión de esta legislación alejada de los principios federales de la Constitución Nacional.

En materia de educación, es evidente el proceso de centralización operado, con violación de las normas constitucionales respectivas. Con la sanción de la Ley General de Educación y de la Ley de Financiamiento Educativo se afectaron las bases de nuestra ley suprema y se ha producido una notoria centralización, que modificó el proceso histórico anterior, que tendía a un sistema federal educativo. Se ha señalado ${ }^{53}$ que hubo hitos en tal sentido, como los del presidente Frondizi en 1957, que dispuso por decreto la transferencia de las escuelas primarias nacionales a las provincias, lo que se concretaría posteriormente en la década de los setenta,

52 Véase el documentado trabajo de Lorena Schiariti titulado "Oscilaciones del federalismo en materia de hidrocarburos", en la Revista de Derecho Público "Diez Años de Derecho Público en la Argentina-II', 2013-2, directores Tomás Hutchinson y Horacio Rosatti, pp. 409 y ss., Buenos Aires, Rubinzal Culzoni Editores, 2012.

53 Por parte de Ricardo César Iturrez, Educación, un derecho de todos, Buenos Aires, Editorial Mda y Univesidad Fasta, 2013. 
Esta revista forma parte del acervo de la Biblioteca Jurídica Virtual del Instituto de Investigaciones Jurídicas de la UNAM

aunque sin asignarse los fondos pertinentes. Este proceso de federalización recibió un impulso decisivo en el Congreso Pedagógico Nacional, convocado por el presidente Alfonsín, en cuyas conclusiones aprobadas en 1988 se hizo expresa referencia a los principios federales en materia educativa. Ello originaría ya en 1991 la sanción de la Ley 24,049 de Transferencia de los Servicios Educativos, donde las provincias se hicieron cargo de las escuelas de nivel medio y terciario que dependían del Ministerio de Educación de la Nación, aunque lamentablemente, sin los fondos respectivos, lo que originaría nuevos desequilibrios fiscales en nuestra Federación.

También se han señalado como otros hitos en este proceso de descentralización operativa en la materia: la sanción de la Ley Federal de Educación 24,195 por parte del Congreso Nacional; el Pacto Educativo, celebrado entre la Presidencia y los gobernadores en la provincia de San Juan en 1994, y, por último, la reforma constitucional de $1994 .{ }^{54}$

Pero desafortunadamente a partir de 2003 — refiere este autor — 55 se produjo una nueva vuelta al "centralismo educativo", mediante la sanción de una serie de normas, hasta llegar a la vigente Ley Nacional de Educación 26,206 de 2006, que derogó la Ley Federal de Educación, y que otorgó importantes atribuciones al Ministerio de Educación de la Nación. Un ejemplo de ello es la incomprensible facultad otorgada al ministro de dicha área, de declarar en emergencia educativa las jurisdicciones provinciales, lo que demuestra en forma palmaria la centralización imperante. Y lo propio puede sostenerse sobre la Ley de Financiamiento Educativo, que también afectó la coparticipación impositiva de las provincias. En la propuesta siguiente continuamos con este tema educativo.

Asimismo, se pueden formular objeciones constitucionales por violación del federalismo, a la Ley 26.522 de Servicios de Comunicación Audiovisual. En efecto, se han impuesto criterios centralistas y unitarios, en los artículos 1o., 7o. y concordantes, que avasallan las competencias provinciales en la materia, con base en los artículos 121 y 32 de la Constitución Nacional. Recordemos que sólo lo comercial interprovincial puede ser competencia federal, según lo dispuesto en el artículo 75, inciso 13, de

54 Iturrez, op. cit., cap. VIII "El federalismo educativo en Argentina", pp. 287 y ss.

55 Ibidem, cap. XII "Análisis de la Ley de Educación Nacional 26.206”, pp. 477 y ss. 
Esta revista forma parte del acervo de la Biblioteca Jurídica Virtual del Instituto de Investigaciones Jurídicas de la UNAM

la ley suprema, y, en consecuencia, no cabe dudar de las potestades provinciales al respecto dentro de los límites respectivos. ${ }^{56}$

Por otra parte, cuando se observa la composición del AFSCA (Autoridad Federal de los Servicios de Comunicación Audiovisual), en el artículo 14 de la Ley, sobre siete miembros designados por el Poder Ejecutivo de la Nación, hay sólo dos propuestos por el Consejo Federal. Y en cuanto a la composición de este último órgano (artículo 16 de la Ley), si bien cada provincia y la Ciudad Autónoma de Buenos Aires pueden designar un representante, el peso político e institucional de esta participación provincial resulta disminuido, porque además hay catorce representantes más de otras entidades. Por otra parte, en la comparación de atribuciones del AFSCA y del Consejo resulta evidente que este último ha sido claramente desfavorecido en perjuicio de aquélla, donde a su vez predomina notablemente el Poder Ejecutivo.

Señalamos especialmente otra decisión centralista, que es menester derogar: la Ley 26.853 de Creación de las Cámaras de Casación. Sin poder detenernos en el análisis de la cuestión, sólo señalamos que esta normativa demorará y encarecerá enormemente los juicios, especialmente para los ciudadanos del interior del país, que deberán litigar en la ciudad de Buenos Aires, con violación del federalismo y de la tutela judicial efectiva. ${ }^{57}$ En torno a esto, no podemos dejar de manifestar igualmente nuestro más profundo rechazo a otra propuesta unitarizante: la creación de un tribunal constitucional, porque ello afectaría nuestro federalismo judicial, asentado además en el control de constitucionalidad difuso, que es preciso mantener.

56 No alcanza bajo nuestro punto de vista para superar la objeción formulada, la disposición del artículo 163 de la Ley, que con el título de Limitaciones, expresa: "Las jurisdicciones provinciales, la Ciudad Autónoma de Buenos Aires y las Municipalidades no podrán imponer condiciones de funcionamiento y gravámenes especiales que dificulten la prestación de los servicios regulados en esta ley, sin perjuicio de sus propias competencias". Es que la última frase resulta controvertida por las anteriores, donde se reafirma el avasallamiento del gobierno nacional.

57 Por eso destacamos el criterio descentralizador del reciente fallo de la Corte Suprema de Justicia de la Nación en el caso "Pedraza", que ha resuelto que cada Cámara federal del país pueda entender en las causas de los jubilados, modificando la situación actual, donde sólo intervenía la Cámara Federal de la Seguridad Social, ubicada en Buenos Aires. Véase asimismo lo expuesto sobre este tema en la propuesta 4. 
Otro amplio campo normativo y de políticas que es necesario modificar es el vinculado al poder de policía, ya que aquí se ha verificado otra ostensible violación de los principios constitucionales federales. Ello, debido a las siguientes razones expuestas por Susana Cayuso: ${ }^{58}$

1. Una interpretación extremadamente amplia y flexible de las facultades delegadas al gobierno central, que en la práctica significa estrechar el ámbito de las atribuciones reservadas por las provincias. 2. Un avance en los límites de la facultad reglamentaria del Estado nacional en materias propias del derecho común. 3. Una interpretación desnaturalizadora de las facultades concurrentes, con preeminencia de la facultad reguladora del gobierno central, con desmedro de las facultades de las provincias y casi excluyente de la coexistencia dispuesta constitucionalmente.

\section{Seguidamente, la autora dice:}

En todos los casos el avance se justifica en el ejercicio del poder de policía. Se perfeccionó así, la concentración reglamentaria en cabeza del poder central, se institucionalizó la regla de la absoluta discrecionalidad política, se entronizó la doctrina de la emergencia económica, se ha desvirtuado el contenido y la extensión de las facultades concurrentes y el resultado es el debilitamiento institucional de las provincias. ${ }^{59}$

58 Cayuso, Susana, "El federalismo y el poder de policía", en el libro Aspectos jurídicos e institucionales del federalismo argentino, director Antonio María Hernández, Instituto de Federalismo de la Academia Nacional de Derecho y Ciencias Sociales de Córdoba, 2011, pp. 92 y 93 .

59 Ibidem, p. 93. Más adelante, la profesora de la Universidad Nacional de Buenos Aires recuerda las palabras agudas y proféticas pronunciadas por un gran constitucionalista que también fue diputado de la Nación como Juan González Calderón, al respecto: “...los legisladores nacionales se resbalan por el plano inclinado de teorizaciones exóticas y peligrosas para el porvenir de nuestras instituciones federales, orientándose visiblemente, y tal vez inconscientemente, en el sentido de unitarizar el país, saltando sobre las barreras de la Constitución, con el correlativo aniquilamiento de las autonomías provinciales por la fuerza expansiva de una legislación usurpadora e inadecuada. Ya ha hecho mucho el Congreso contra la realidad de las autonomías provinciales, disminuyéndolas y sometiéndolas bajo la coerción de leyes usurpadoras de sus más esenciales derechos, para imponer normas o reglamentaciones unitarizantes”. Y luego de hacer referencia a la nota de Vélez Sársfield del artículo 2611 del Código Civil, al defender las facultades reglamentarias de las provincias de los códigos de fondo, sostuvo: "No debe despreciarse esta ventaja que, entre otras, tiene el federalismo: permite a cada región del país, a cada provincia, arreglar su vida local en la forma que consulte más provechosamente los intereses y las características del respectivo 
Esta revista forma parte del acervo de la Biblioteca Jurídica Virtual del Instituto de Investigaciones Jurídicas de la UNAM

Se comprende, en consecuencia, la magnitud y profundidad de los cambios que hay que realizar - tanto normativos como jurisprudenciales - para alcanzar la plena vigencia de nuestra Constitución federal en esta materia.

\section{FeDERALIZAR LA EDUCACiÓN}

\section{Sostiene Juan José Llach: ${ }^{60}$}

La educación es la clave para lograr un país sin pobreza, con mayor integración social y más equitativo y, al mismo tiempo, un desarrollo productivo con crecientes contenidos de capital humano, ciencia y tecnología que incentiva a producir y exportar bienes y servicios calificados y no el capital humano mismo, como ha ocurrido tan frecuentemente durante los últimos cincuenta años. El objetivo "social" no se contrapone con el objetivo "económico": se trata de un mismo proceso.

Y frente a las dificultades de las provincias para tener un adecuado sistema educativo, expresa: "Para lograr el pleno acceso de la Argentina a la sociedad del conocimiento es imprescindible federalizar ampliamente la distribución de la renta fiscal y de allí la propuesta de un Fondo para el Desarrollo Humano con sentido regional, provincial y local". ${ }^{61}$

Compartimos estas ideas y convicciones acerca de la enorme importancia de la educación para cambiar la deprimente realidad que presenta nuestro país. Y en relación con ésta y con las profundas desigualdades existentes, que muestran otra faceta negativa de nuestra federación, ha escrito Alieto Guadagni: ${ }^{2}$

pueblo... Lo alarmante, para quien mira sin apasionamiento la expansión progresiva del poder central, es comprobar cómo se destruyen desde el Congreso no ya los cimientos jurídicos y políticos de nuestras instituciones federales, sino también la posibilidad de que la legislación local pueda consultar, con más conocimiento del ambiente y más eficacia, las peculiaridades de cada provincia en beneficio de sus habitantes, fomentando el progreso y el bienestar colectivos... Qué quedará de las autonomías provinciales si se les arrebatan sus poderes de policía? Para qué servirán después esas autonomías? Cuáles serán las razones de su existencia constitucional?”" (op. cit., pp. 95 y 96).

60 Llach, Juan José, "Federales y unitarios en el siglo XXI”, cit., p. 238.

61 Ibidem, p. 239.

62 Guadagni, Alieto, "Educar para superar la desigualdad", La Nación, 30 de abril de 2014 
Esta revista forma parte del acervo de la Biblioteca Jurídica Virtual del Instituto de Investigaciones Jurídicas de la UNAM

Las evidencias del Ministerio de Educación, por provincia y tipo de escuela, son las siguientes: (1) el 36\% de los alumnos de sexto grado primario no sabe Matemática; sin embargo, este indicador negativo se ubica en apenas 8\% en las escuelas primarias privadas de la ciudad de Buenos Aires y trepa al 51 en las escuelas estatales en el conurbano y Formosa. (2) El 45\% de los alumnos del último año del secundario no sabe Matemática; pero en muchas provincias del NOA y del NEA este porcentaje en las escuelas estatales se ubica entre 70 y $80 \%$, mientras que en las escuelas privadas de La Pampa apenas llega al 17\%. (3) La considerable deserción de la escuela secundaria está íntimamente vinculada al nivel socioeconómico de las familias. De cada 100 alumnos que ingresaron a primer grado en el país en 2001 se graduaron 33 en 2012; pero esta cifra no refleja bien la realidad, ya que mientras las escuelas privadas graduaron 64, las estatales apenas graduaron 25. Esta significativa desigualdad es aún mayor en muchas provincias, como Santiago del Estero, donde apenas se graduaron en escuelas estatales 17, o en Misiones, donde la graduación secundaria fue de apenas 15 alumnos cada 100 ingresantes en primer grado.

No cabe dudar, en consecuencia, sobre el carácter estratégico que tiene la educación para el cambio de nuestro país y la plena vigencia de la república federal consagrada en la Constitución Nacional, con igualdad de oportunidades en todo el territorio.

Y por eso insistimos nuevamente ${ }^{63}$ en la importancia de la educación cívica y democrática, como tarea esencial de la democracia, según enseñaba Hans Kelsen. Abogamos por un cambio profundo de nuestros usos y costumbres con altas dosis de violencia, a los fines de la elevación de nuestra cultura democrática y de la legalidad.

Para tener "ciudadanos activos", Norberto Bobbio postuló un "llamamiento a los valores", ${ }^{64}$ señalando en primer lugar al ideal de la tolerancia, ${ }^{65}$ seguido por el de la no violencia, ${ }^{66}$ el de la renovación gra-

63 Como lo hicimos en nuestra obra ya citada "Fortalezas y debilidades constitucionales. Una lectura crítica en el Bïcentenario", pp. 158-160 y 166 y 167.

64 Bobbio, Norberto, El futuro de la democracia, Barcelona, Plaza \& Janes, 1985, p. 48.

65 "Si hoy existe una amenaza para la paz del mundo, ésta viene una vez más del fanatismo, o bien de la ciega creencia en la verdad y en la fuerza capaz de imponerla. Huelga dar ejemplos: los tenemos antes nuestros ojos" ( $c f r$. Bobbio, Norberto, op. cit., p. 48).

66 "Jamás he olvidado la enseñanza de Karl Popper, según la cual, lo que distingue esencialmente a un gobierno democrático de otro no democrático es el hecho de que sólo 
dual de la sociedad a través del libre debate de las ideas y el cambio de las mentalidades y del modo de vivir, ${ }^{67}$ y finalmente, el ideal de la hermandad (la fraternité de la Revolución francesa) ${ }^{68}$

Ese cambio debe ser promovido por nuestra educación popular como el accionar más urgente a desarrollar según Víctor Massuh-, ${ }^{69}$ y podría ser acelerado por los ejemplos que brinde una dirigencia de gran formación y compromiso ético y republicano.

Insistimos en que la educación debe basarse especialmente en el conocimiento de los principios y valores de la Constitución Nacional y de su sistema republicano y federal. ${ }^{70}$

en el primero los ciudadanos se pueden desembarazar de sus gobernantes sin derramamiento de sangre. Las tan escarnecidas reglas formales de la democracia han introducido, por primera vez en la historia, técnicas de convivencia, cuyo objeto es el de resolver los conflictos sociales sin recurrir a la violencia. Sólo allí se respetan estas reglas, el adversario no ya un enemigo (que debe ser destruido), sino un opositor, que mañana podrá ocupar nuestro lugar" ( $c f r$. Bobbio, Norberto, op. cit., p. 48).

67 "Sólo la democracia permite la formación y la expansión de las revoluciones silenciosas, como ha ocurrido en estos últimos decenios con la transformación de la relación entre los sexos, que tal vez sea la mayor revolución de nuestros tiempos" (cfr. Bobbio, Norberto, op. cit., pp. 48 y 49).

68 "Gran parte de la historia está hecha de luchas fratricidas. En su Filosofía de la Historia, Hegel define la historia como un «inmenso matadero» ¿Acaso podemos quitarle la razón? En ningún país del mundo puede perdurar el régimen democrático sin convertirse en una costumbre. Pero ¿puede convertirse en una costumbre sin el reconocimiento de la hermandad que une a todos los hombres en un destino común? Se trata de un reconocimiento mucho más necesario hoy, en que cada día nos hacemos más consientes de este destino común, por lo cual deberemos, guiándonos por ese podo de luz de razón que ilumina nuestro camino, actuar en consecuencia" ( $c f r$. Bobbio, Norberto, op . cit., p. 49).

69 "Se trata de una docencia democrática a vivirse en el hogar, en el seno de los partidos, en la universidad, en las calles, en el municipio, en las instituciones, en las urnas. Reconocer que la democracia es una gimnasia cotidiana, un estado de espíritu que comienza con este doble movimiento: la aceptación de la disidencia y el reconocimiento de que un orden justiciero es fruto del esfuerzo común y no de una ofrenda providencial". (Massuh, Víctor, La argentina como sentimiento, Editorial Sudamericana, pp. 153 y 154).

70 Como lo dispuso la Ley 25.863 de 2003, sancionada por el Congreso a propuesta de la Asociación Argentina de Derecho Constitucional que en ese entonces presidíamos, al establecer el 1o. de Mayo como Día de la Constitución Nacional. Desafortunadamente, como en tantos otros casos, tampoco se cumple esta normativa tan importante para nuestra educación cívica y democrática. 
Esta revista forma parte del acervo de la Biblioteca Jurídica Virtual del Instituto de Investigaciones Jurídicas de la UNAM

\section{EJERCER UN FEDERALISMO DE CONGERTACIÓN PARA LA EXPLORACIÓN, EXPLOTACIÓN Y APROVECHAMIENTO DE LOS RECURSOS NATURALES}

El reconocimiento expreso del dominio originario de los recursos naturales de las provincias, efectuado por la Convención de Santa Fe y Paraná de 1994, en el artículo 124 de la ley suprema, debe observarse como una contundente expresión del fortalecimiento del federalismo argentino, que fue una de las grandes ideas-fuerza de la reforma.

Y con respecto a la extensión del dominio de los recursos naturales por las provincias, dijimos en la Convención Constituyente, en nombre de la Comisión de Redacción, en el debate en particular de la norma:

Cuando nos referimos al alcance de lo que corresponde a las provincias en cuanto al dominio de los recursos naturales existentes en su territorio, la Comisión interpreta que el territorio comprende tanto el suelo, como el subsuelo, el espacio aéreo y el litoral marítimo. Por supuesto, también son de dominio de las provincias los recursos renovables o no. ${ }^{71}$

Esta clara definición constitucional sobre el dominio de los recursos naturales por las provincias en sus respectivos territorios ha significado un cambio trascendental para afirmar el federalismo económico, pero todavía no ha podido efectivizarse por la inacción legislativa y la falta de una adecuada jurisprudencia. ${ }^{72}$

Aclaramos además que para nosotros, por la reforma constitucional producida, la legislación centralista debió perder sus efectos, por una ele-

71 Diario de Sesiones de la Convención Nacional Constituyente, Santa Fe-Paraná, 1994, tomo IV, p. 3864. Uno de los temas más importantes es el del mar, donde ya no pueden quedar dudas sobre dominio de las provincias costeras, tal como lo venían señalando antes de la reforma Frías, Bidart Campos, Díez y Marienhoff, entre otros autores. El Congreso también deberá modificar el alcance de la jurisdicción provincial en el mar, así como avanzar en fórmulas asociativas con la nación, para la explotación de los recursos inmensos de la "zona económica exclusiva" que se extiende hasta las doscientas millas.

72 Es evidente que el Congreso no produjo las reformas legales pertinentes, para la adecuación a la ley suprema. Asimismo, en cuanto a la jurisprudencia, señalamos el fallo de la Corte Suprema de Justicia de la Nación en el caso "Total", en 2003, donde no se reconoció dicho alcance del territorio de la provincia de Tierra del Fuego para poder percibir tributos sobre las explotaciones petrolíferas que realiza la empresa en el mar. 
Esta revista forma parte del acervo de la Biblioteca Jurídica Virtual del Instituto de Investigaciones Jurídicas de la UNAM

mental aplicación de la gradación normativa, determinada por el artículo 31 de la ley suprema de la nación. Sin embargo, ya vimos anteriormente el caso de los hidrocarburos, entre otros, como demostración de la anomia que nos caracteriza

Más allá de esto, la reforma constitucional no sólo dispuso cambios sustanciales en esta materia, con respecto al dominio de los recursos naturales (como el mar, hidrocarburos, minerales, los recursos hídricos y la energía), sino también sobre la jurisdicción. Un ejemplo notable en este último aspecto es la modificación efectuada en el artículo 75, inciso 30, que deja a salvo el ejercicio de los poderes de policía y de imposición de provincias y municipios en los establecimientos de utilidad nacional, siempre que no interfieran su específica finalidad, lo que reviste especial trascendencia para el futuro del federalismo.

Con base en lo expuesto, consideramos que para la exploración, explotación y aprovechamiento de los recursos naturales, con un concepto de desarrollo sustentable, se abre un campo amplísimo para el federalismo de coordinación o concertación, mediante la utilización de las relaciones y entes interjurisdiccionales.

Es necesario producir una modernización institucional que sume los esfuerzos de todos los niveles gubernamentales interesados, en una sinergia que nos permita alcanzar soluciones sustentables en el aprovechamiento del mar, de la pesca, de los hidrocarburos, de los minerales y de otros recursos naturales. ${ }^{73}$

\section{FEDERALIZAR LOS SERVICIOS PÚBLICOS DE GOMPETENCIA NAGIONAL}

No obstante que la reforma constitucional de 1994 dispuso en el artículo 42 - al regular los derechos de usuarios y consumidores - la participación de las provincias en los organismos de control de los servicios públicos de competencia nacional, ${ }^{74}$ no se han podido verificar modificaciones en esta materia, donde han continuado las políticas centralistas. Todo ello, con inexcusable responsabilidad no sólo de las autoridades federales, sino

73 Véase Hernández, Antonio María, "El federalismo, ausente en el impulso de YPF", nota publicada en Clarín, Buenos Aires, 8 de julio de 2014, Opinión, p. 25.

74 Entre los que se destacan los de gas, aeropuertos y transporte en sus diversas modalidades. 
Esta revista forma parte del acervo de la Biblioteca Jurídica Virtual del Instituto de Investigaciones Jurídicas de la UNAM

también de las provinciales, como bien lo han señalado Alejandro Pérez Hualde $^{75}$ y Nidia Karina Cicero. ${ }^{76}$

Este otro incumplimiento del proyecto federal se debió a distintas razones, como ha puntualizado esta autora: ${ }^{77}$ efectivamente, no han participado las provincias en dichos organismos de control; que además han sido desnaturalizados por su falta de independencia, que en algunos casos fueron creados por decreto y no por leyes del Congreso, y, finalmente, por la inexistencia de una participación adecuada de ciudadanos y usuarios y consumidores, que hubiera permitido un buen funcionamiento de los servicios con un sistema regulatorio eficaz.

Mirando al futuro, Cicero ${ }^{78}$ propone para asegurar la participación provincial en estos servicios: a) la intervención en el diseño de la regulación, esencialmente a través del debate legislativo, lo que implica la imposibilidad del dictado de decretos del Poder Ejecutivo y la derogación de la legislación de emergencia económica, y b) la intervención en el control de gestión, a través de las siguientes alternativas: 1) integración de los entes reguladores nacionales por representantes de las provincias involucradas; 2) delegación de la facultad de control de ciertos aspectos de la regulación federal en organismos locales; 3) cooperación provincial en el control del servicio público federal a través de la detección y comunicación de incumplimiento a los organismos provinciales competentes.

Y para concretar esta participación, la autora sostiene la necesidad de una relectura de las facultades concurrente en materia de control o poder de policía, la celebración de acuerdos interjurisdiccionales y la transferencia a la órbita provincial de servicios actualmente regulados a nivel nacional. ${ }^{79}$

75 Pérez Hualde, Alejandro, "Servicios públicos en el constitucionalismo provincial", en el libro Aspectos jurídicos e institucionales del federalismo argentino, director Antonio María Hernández, Córdoba, editado por el Instituto de Federalismo de la Academia Nacional de Derecho y Ciencias Sociales de Córdoba, 2000.

76 Cicero, Nidia Karina, Servicios públicos y federalismo. Análisis de una historia de conflictos y una propuesta de superación, Buenos Aires, Eudeba, 2013. Se trata de la tesis doctoral de la autora, dirigida por el doctor Alejandro Pérez Hualde, con un estudio profundo de tan trascendente cuestión, estrechamente ligada al federalismo de coordinación o concertación.

\footnotetext{
77 Ibidem, p. 336.

78 Ibidem, pp. 339 y ss.

79 Ibidem, pp. 341 y ss.
}

D. R. C 2016. UNAM, Instituto de Investigaciones Jurídicas, Boletín Mexicano de Derecho Comparado, núm. 146, pp. 375-418. 
Esta revista forma parte del acervo de la Biblioteca Jurídica Virtual del Instituto de Investigaciones Jurídicas de la UNAM

\section{AFIANZAR LOS PRINCIPIOS FEDERALES EN LA DOGTRINA Y ORGANIZAGIÓN DE LOS PARTIDOS POLÍTICOS}

Consideramos que al haberse constitucionalizado los partidos políticos en el artículo 38 - otra obra de la reforma de 1994-, con la obligación de respetar la ley suprema, los mismos deben aceptar, practicar y defender los valores y principios del federalismo no sólo en la organización estatal, sino también en su propia organización y funcionamiento.

Es que otra de las causas de la desfederalización del país ha sido la falta de cumplimiento adecuado de estos principios por parte de los partidos políticos, especialmente por su actuación en el Congreso, y en particular en el Senado. ${ }^{80}$

Interrelacionado con ello, el hiperpresidencialismo, la democracia delegativa y las emergencias, degradaron nuestra calidad institucional, impidieron la plena vigencia de la democracia deliberativa y de los principios republicanos y federales ${ }^{81}$ y afectaron profundamente los partidos políticos.

A su vez, ese hiperpresidencialismo ha significado en no pocos casos la confusión de partido oficialista y gobierno. Incluso en algunos casos se han llegado a confeccionar las listas de legisladores desde la Presidencia, como demostración indudable de centralismo. Y el mismo fenómeno se ha repetido en los niveles provinciales y municipales, con los gobernadores e intendentes.

Por eso Barrera Buteler concluye en que las deficiencias del federalismo argentino tienen una raíz ética y cultural, antes que normativa, ya que los representantes en el Congreso no responden a las provincias y a sus intereses, sino al proyecto político del dirigente que lo incluyó en la lista. ${ }^{82}$

De ahí que el autor proponga que se introduzcan mayores exigencias legales para el reconocimiento de partidos políticos nacionales en relación con el federalismo, que se disminuya el efecto "arrastre" que se produce

80 Recuérdese lo expuesto en la propuesta 3 sobre el fortalecimiento del rol del Congreso y Senado en particular.

81 Remitimos a la nota 13. Véanse también los trabajos de Sabsay, Daniel Alberto, "Consideraciones en torno al federalismo argentino" y Midón, Mario, "Ilegitimidades constitucionales en nombre del federalismo", en el libro Aspectos históricos y políticos del federalismo argentino, director Antonio María Hernández, cit., pp. 247 y ss. y 271 y ss., respectivamente.

82 Barrera Buteler, Guillermo, "Aspectos políticos del federalismo", en el libro Aspectos históricos y políticos del federalismo argentino, director Antonio María Hernández, cit., p. 287. 
Esta revista forma parte del acervo de la Biblioteca Jurídica Virtual del Instituto de Investigaciones Jurídicas de la UNAM

por las elecciones nacionales, provinciales y municipales conjuntas y que se fortalezca el vínculo entre representante y representado. ${ }^{83}$

Por nuestra parte, desde hace tiempo somos partidarios de una profunda reforma política, ${ }^{84}$ con especial énfasis en los partidos políticos y en el sistema de partidos. ${ }^{85}$

Creemos que hay que avanzar en la misma ${ }^{86}$ en los aspectos relativos al sistema electoral, ${ }^{87}$ a la organización de las elecciones - que no pueden seguir estando en las manos del Ministerio del Interior ${ }^{88}$ e incluso, de la propia justicia electoral, con especial énfasis en su fortalecimiento e independencia.

En lo específicamente electoral, estimamos negativamente las reelecciones indefinidas que se permiten en varias provincias y en gran parte de los municipios del país. Ellas consolidan el hiperpresidencialismo, terminan afectando el sistema republicano y democrático e impiden la renovación de las dirigencias.

Estamos convencidos de que la parte sustancial de una reforma política reside en la mayor democratización, modernización y fortalecimiento

83 Barrera Buteler, Guillermo, op. cit., p. 288.

84 Para un análisis completo de la reforma política en América Latina, véase especialmente la tesis doctoral en ciencia política de Daniel Zovatto, presentada en la Universidad Complutense de Madrid, en 2011, titulada La reforma político-electoral durante la tercera ola democrática en América Latina, que abarca el periodo 1978-2009, entre otros trabajos de dicho autor. Asimismo, Reforma política y electoral en América Latina 1978-2007, Zovatto, Daniel y Orozco Henríquez, Jesús (coords.), México, UNAM, Instituto de Investigaciones JurídicasInternacional IDEA, 2008.

85 Hernández, Antonio María y Belisle, José Manuel, "Regulación jurídica de los partidos políticos en Argentina", en Zovatto, Daniel (coord.), Regulación jurídica de los partidos políticos en América Latina, México, UNAM, Instituto de Investigaciones Jurídicas-Internacional IDEA, 2006, pp. 191-242, y antes, "Por una profunda reforma política", La Voz del Interior, Córdoba, 23 de diciembre de 2000.

86 Como lo hemos propuesto en nuestras obras Fortalezas y debilidades constitucionales, cit., p. 159, y Federalismo y constitucionalismo provincial, cit., cap. XVII "La Constitución de Córdoba y la reforma política", pp. 457 y ss.

87 Nuestro país posiblemente sea el más atrasado de América Latina en esta materia, ya que todavía continúa con el sistema de boletas múltiples, con todas las corruptelas que ello permite. Y ello rige en casi todos los órdenes gubernamentales, con pocas excepciones, como en las provincias de Córdoba y Santa Fe, con boleta única, y algunas otras experiencias municipales de voto electrónico.

88 Es muy interesante observar la experiencia mexicana al respecto, con su Instituto Federal Electoral, que significara un notable avance en esta materia. 
Esta revista forma parte del acervo de la Biblioteca Jurídica Virtual del Instituto de Investigaciones Jurídicas de la UNAM

de los partidos políticos. Se deben abrir los partidos y profundizar la democracia interna, para superar la denominada "ley de hierro de las oligarquías partidarias". ${ }^{89} \mathrm{Y}$ ponerse el énfasis en el eficaz cumplimiento de sus funciones, como instituciones fundamentales de nuestro sistema democrático, como lo dice el artículo 38. En este aspecto, consideramos plausible la selección de candidatos en el orden federal, a través de elecciones internas abiertas simultáneas y obligatorias, que deben extenderse a los órdenes provinciales y municipales. Las cuestiones de la financiación de la política son trascendentes, porque están vinculadas a uno de nuestros más graves problemas: la corrupción. ${ }^{90}$ Otro aspecto decisivo es la formación y capacitación de la dirigencia de los partidos políticos. En este sentido, se debería dar estricto cumplimiento al artículo 38 de la Constitución Nacional que ha previsto la asignación de fondos a los partidos políticos con esta finalidad..$^{91}$

Queremos destacar especialmente un aporte para nuestra provincia, que creemos puede ser útil para otras y para el resto de nuestros órdenes gubernamentales: el profundo estudio realizado por la Comisión Consultiva de Expertos para la Reforma Político Electoral, que culminara con un dictamen y la edición de una obra. ${ }^{92}$

89 Como lo sostuviera Robert Michels.

90 Véase nuestra obra Fortalezas y debilidades constitucionales..., cit., pp. 151-156 y 167 y 168.

91 Recordamos las opiniones de Weber y de Ortega y Gasset sobre las exigencias y condiciones para ser un político en serio, ya que se requiere conjuntamente una extraordinaria capacidad de pensamiento y de acción. Y frente a la complejidad del mundo moderno, hacen falta verdaderas carreras políticas, centros de investigación y de pensamiento en los partidos, además de escuelas de formación para los jóvenes y los dirigentes. Esta reforma es particularmente urgente en nuestro país, ante el más que preocupante estado de situación de nuestros partidos y del sistema de partidos.

92 Titulada Asi no va más. Diagnóstico y propuesta de reforma político-electoral de la provincia de Córdoba, dictamen de la Comisión Consultiva de Expertos, editado por las universidades Católica y Nacional de Córdoba y la Educc (Editorial de la Universidad Católica de Córdoba), Córdoba, 2008. Dicha Comisión fue presidida por el doctor Daniel Zovatto, e integrada por los rectores de ambas universidades, Carolina Scotto y Rafael Velasco, los decanos Ramón P. Yanzi Ferreyra y Mario Riorda, los profesores Jorge Gentile y el suscrito, y la doctora Claudia Laub, de la organización no gubernamental El Ágora. Allí se propuso una reforma constitucional y otras reformas legislativas y ejecutivas, para modificar todos los aspectos de la reforma político-electoral, abarcando no sólo el orden provincial, sino también el municipal. Por razones de brevedad, nos remitimos a dicho libro para el análisis de dicha temática. Desafortunadamente, muy pocas propuestas se 
Esta revista forma parte del acervo de la Biblioteca Jurídica Virtual del Instituto de Investigaciones Jurídicas de la UNAM

En directa relación con el federalismo, hemos señalado la necesidad de su profundización mediante la existencia de partidos políticos específicamente provinciales y municipales, ${ }^{93}$ que consideramos muy importantes para vigorizar y jerarquizar la política y la autonomía en dichos ámbitos gubernamentales, mediante el análisis y debate de los temas respectivos.

Coincidiendo con Joaquín V. González, que decía que los municipios eran el "primer teatro" en que los hombres ejercían sus derechos, sostuvimos que los gobiernos locales autónomos y ampliamente participativos deben ser "la escuela social de la democracia" y el escenario donde debe comenzar el cursus honorum de la política. Deben ser, porque todavía no lo son, ya que aunque ha sido notable el avance de nuestra legislación para posibilitar una democracia participativa en lo local, en los hechos se observan preocupantes problemas al respecto, por nuestra baja calidad institucional. $^{94}$

Además de ello, es cada vez mayor la importancia que la política provincial y aun la municipal tiene en el contexto nacional. Adviértase que la mayoría de quienes fueron presidentes - luego de la recuperación de-

concretaron, entre las que contamos la eliminación de la sumatoria de votos y la consagración de la boleta única. Pero confiamos en que algún día dicho estudio producirá muchos mayores cambios en nuestra provincia y en nuestros gobiernos locales. Véase María Hernández, Antonio, Federalismo y constitucionalismo provincial, cit., cap. XVII "La Constitución de Córdoba y la reforma política", pp. 457 y ss.

93 En nuestra obras, Derecho municipal, 2a. ed., Buenos Aires, Depalma, 1997 y Derecho municipal. Parte general, México, UNAM, 2003, en respectivos capítulos sobre la participación ciudadana en el municipio, donde analizamos el tema de los partidos políticos, entre otras formas de participación tanto específicamente políticas como de carácter ciudadano.

94 Además de la participación estrictamente política por el reconocimiento de los derechos políticos de elegir y ser elegido para ciudadanos e incluso extranjeros, de formar partidos políticos locales y de ejercitar institutos de democracia directa o semidirecta como la iniciativa, el referendum y la revocatoria, las Constituciones provinciales, leyes orgánicas municipales y cartas orgánicas municipales, en general han posibilitado el ejercicio de otras formas de participación, que denominamos ciudadanas. Entre ellas destacamos la vecinal, a través de centros y consejos vecinales; la de audiencias públicas; la de consejos económicos y sociales, entre otras ( $c f r$. nuestras obras citadas en la nota anterior). Con respecto a nuestros problemas de baja calidad institucional, obsérvense las diversas encuestas y estudios sobre la crisis de la participación y de la representación y la debilidad que exhibimos en cultura constitucional y de la legalidad (véase Zovatto, Daniel, Mora y Araujo, Manuel et al., Encuesta de cultura constitucional: Argentina, una sociedad anómica, cit.). 
Esta revista forma parte del acervo de la Biblioteca Jurídica Virtual del Instituto de Investigaciones Jurídicas de la UNAM

mocrática de 1983-, antes fueron gobernadores o jefe de Gobierno de la Ciudad Autónoma de Buenos Aires. ${ }^{95}$

Y lo propio puede decirse de la trascendencia de la política municipal. En este sentido, no podemos dejar de considerar lo que ocurre en la provincia de Buenos Aires, por su especial peso político. Es para nosotros imperioso que se modifique el régimen municipal, no sólo para asegurar la autonomía, ${ }^{96}$ sino también la descentralización política y democrática provincial. Desde hace tiempo venimos sosteniendo que hay que cambiar el sistema centralista de un solo gobierno municipal por partido, que significa la existencia de apenas 135 para más de 307,000 km² y de 16,000,000 de habitantes. La democracia local debe profundizarse en dicha provincia con muchos más municipios autónomos y participativos. ${ }^{97}$

Reiteramos la imprescindible necesidad de una metodología interdisciplinaria para el estudio del federalismo, ${ }^{98}$ que ya está produciendo frutos, como se aprecia en los aportes provenientes de politólogos que enriquecen con su análisis el conocimiento de una temática tan compleja, como la que nos ocupa. ${ }^{99}$

95 La politóloga Julieta Suárez Cao titula uno de sus trabajos "Federal en la teoría y unitaria en la práctica? Una discusión sobre el federalismo y la provincialización de la politica", Revista SAAP, vol. 5 núm. 2, noviembre de 2011, pp. 305-321. Asimismo, Alberto Dalla Via, profesor de derecho constitucional y miembro de la Cámara Nacional Electoral, analizó la territorialización de la política en su libro La competencia política en el federalismo argentino, Buenos Aires, Eudeba, 2010.

96 Consagrada constitucionalmente en el artículo 123, como obligación para las provincias. También es lamentable la violación en que también se encuentran las provincias de Santa Fe y Mendoza al respecto, que todavía no han adecuado sus textos constitucionales a la ley suprema.

97 Es urgente también realizar allí una reforma político-electoral, a la que antes nos referimos. Y por cierto, deben prohibirse las reelecciones indefinidas.

98 Como lo indican los libros de Aspectos fiscales y económicos del federalismo y Aspectos históricos y políticos del federalismo argentino, ya citados, que cuentan con la participación de especialistas de dichas disciplinas, junto a los provenientes del derecho. Asimismo, creemos en esa clase de metodología para el estudio del derecho constitucional, del constitucionalismo provincial y del derecho municipal, como lo hemos postulado en nuestras obras respectivas antes citadas.

99 Ejemplos de ello son los trabajos de Bonvecchi, Alejandro, "Federalismo fiscal y supervivencia presidencial" y Gervasoni, Carlos, "Transferencias federales y competitividad electoral: la ventaja oficialista de gobernadores en provincias argentinas (1983-2011)", en el libro Consecuencias económicas y políticas del federalismo fiscal argentino, Gervasoni, Carlos y Porto, Alberto (eds.), cit., pp. 35-104. También señalamos la obra El federalismo argentino en perspectiva comparada, Tulia Falletti, Lucas González y Martín Lardone (eds.), Buenos Aires, 
Esta revista forma parte del acervo de la Biblioteca Jurídica Virtual del Instituto de Investigaciones Jurídicas de la UNAM

\section{DescentraLizar E INTEGRAR EL País EN OTROS ASPECTOS}

Se comprenderá que es menester llevar adelante un proceso de descentralización e integración del país que abarca otros aspectos, además de los previamente considerados.

Nos referimos ahora a las obras de infraestructura, transporte y comunicaciones, como elementos decisivos para un desarrollo nacional equilibrado.

Podemos ejemplificarlo en la necesidad de avanzar en los corredores bioceánicos - al norte, al centro y al sur del país - , lo que significa consolidar los pasos cordilleranos que vinculen a Argentina y al Mercosur con Chile ${ }^{100}$ y luego de ahí al Pacífico y al Asia, con el enorme potencial que ello implica para el futuro.

Esto también implica un mejor aprovechamiento de las hidrovías $\mathrm{Pa}$ raná-Paraguay y Paraná-Tieté, que en particular servirán para la vinculación con Brasil, en los corredores señalados.

Por cierto que esta propuesta está relacionada con otras, y particularmente con la integración regional, tanto nacional como supranacional. ${ }^{101}$

En el sistema de transporte, también estimamos como muy necesaria la recuperación de nuestros ferrocarriles, atenta la importancia que alcanzaron y las dimensiones enormes de nuestra geografía.

Por cierto que la infraestructura y los transportes deberán integrar el país, modificando nuestra macrocefalia y de acuerdo con una planificación federal. ${ }^{102}$

Educa, 2013, con énfasis en la relevancia de la política local y territorial en estos tiempos, de la misma manera que lo hace Suárez Cao, previamente citada en la nota 86. Y desde luego, los aportes histórico-políticos de Julio Saguir en su obra Unión o secesión, Buenos Aires, Prometeo, 2007, y los de Natalio Botana, en su clásica obra El orden conservador, entre otros libros y artículos periodísticos de su autoría.

100 Como ya lo disponen tratados celebrados al respecto.

101 Véanse entre otros trabajos de nuestra autoría: el libro Integración y globalización: rol de las regiones, provincias y municipios, Buenos Aires, Depalma, 2000, y los trabajos "Estudio sobre los aspectos jurídico-constitucionales de la regionalización", "Anteproyecto de Tratado de integración regional entre las Provincias de Córdoba, Entre Ríos y Santa Fe", "El gran desafío de la integración regional", "La región y el área metropolitana de Córdoba" y "A diez años de la creación de la región centro", obrantes en el libro Federalismo y constitucionalismo provincial, cit., pp. 531-553.

102 Una prueba de ello es la concentración absurda del transporte aéreo en Buenos Aires, que dificulta y encarece enormemente nuestras conexiones interprovinciales, además 
Esta revista forma parte del acervo de la Biblioteca Jurídica Virtual del Instituto de Investigaciones Jurídicas de la UNAM

La descentralización y la desconcentración del gobierno federal - asentado en Buenos Aires - también podrían llevarse adelante trasladando desde podere ${ }^{103}$ hasta organismos al interior del país. Es muy importante acercar el gobierno y la administración a los ciudadanos, en un país de tan dilatadas dimensiones.

Asimismo, creemos que también es conveniente disminuir la gran concentración que se advierte en muchos ámbitos de la organización empresarial, sindical, cultural, de las comunicaciones y deportiva, porque inciden en la centralización y en las asimetrías que padecemos.

\section{Trasladar la Gapital Federal}

No por ser la última propuesta deja de tener una especial trascendencia para el fortalecimiento de nuestro federalismo.

Es que no se puede desconocer la importancia que en un Estado tiene su capital, y mucho más cuando se trata de uno que es federal, o sea, compartido entre diversos órdenes gubernamentales en la búsqueda de la "unión" de la "diversidad", que requiere de especiales equilibrios. ${ }^{104}$

Ejemplos de ello son los casos de Estados Unidos con Washington, Suiza con Berna, Canadá con Ottawa, Australia con Canberra y más cercanamente, Brasil con Brasilia.

Éste ha sido uno de los temas más complejos y conflictivos de nuestra historia, como lo dijera Félix Luna, ya que la ciudad de Buenos Aires pudo imponer su destino de capital. ${ }^{105}$

de los problemas de nuestra infraestructura vial y ferroviaria. Recuérdense las críticas de Bonifacio del Carril en "Buenos Aires frente al país", por el sistema de embudo de esta última infraestructura, entre otros autores ( $c f r$. Roulet, Elva, La nueva capital, Buenos Aires, Fundación Jorge Esteban Roulet-Centro de Participación Política, 1987, en el punto "El Gran Buenos Aires", pp. 43 y ss.)

103 Como Alemania, que tiene a sus poderes Legislativo y Ejecutivo en Berlín, pero al Tribunal Constitucional en Kalsruhe.

104 Véase nuestra obra ya citada Federalismo y constitucionalismo provincial, cap. I "Los sistemas políticos federales", en el punto 4: "Federalismo: unión y diversidad" (pp. 8 y 9), y el punto 7. "Conceptos y características esenciales de los Estados federales", con las opiniones de Hamilton, Loewenstein, Elazar, Kincaid, Watts y Linares Quintana (pp. 14-16).

105 Nos remitimos a nuestra obra ya citada Federalismo y constitucionalismo provincial, en su cap. V "La Ciudad de Buenos Aires en la reforma constitucional de 1994", punto 1: "Buenos Aires y el país. Síntesis histórica" (pp. 141 y ss.). 
Esta revista forma parte del acervo de la Biblioteca Jurídica Virtual del Instituto de Investigaciones Jurídicas de la UNAM

Hubo, sin embargo, distintas propuestas, como la antes recordada de Sarmiento en Argirópolis, que la ubicaba en la isla de Martín García, como capital de los Estados Unidos del Río de la Plata, integrados por la Confederación Argentina, Paraguay y Uruguay. Además de distintos proyectos de leyes para fijarla en Rosario, Bell Ville y Villa María. ${ }^{106}$

Tal como lo recordamos anteriormente en la propuesta 5, se confirmaron en la realidad los problemas que anticiparon grandes personalidades argentinas y especialmente Alem, con su conocida profecía, ${ }^{107}$ enunciada en el brillante debate con José Hernández, con motivo de la capitalización de Buenos Aires, operada en 1880.

Ya en el siglo XX hubo distintos proyectos para trasladar la capital, ${ }^{108}$ hasta que el presidente Alfonsín en su discurso de Viedma ${ }^{109}$ anunció la presentación de un anteproyecto al Consejo de Consolidación de la Democracia, donde expresó:

Tal como se predijo en su momento, el crecimiento metropolitano ha transformado el sistema político argentino, destruido las bases del federalismo y

106 En el caso de esta última ciudad, se sancionó una ley en 1871 por el Congreso, que así lo disponía, pero fue vetada por el presidente Sarmiento, que hizo lo propio en ese mismo año con otra ley posterior que fijaba la capital en Rosario. Para un análisis histórico de este tema, véase Roulet, Elva, La nueva Capital, Buenos Aires, Fundación Jorge Esteban Roulet, Centro de Participación Política,1987, en el punto "La cuestión capital de la República”, pp. 13 y ss. Previamente, el presidente Mitre había también vetado otra ley que declaraba capital a Rosario.

107 De que iba a ser la "apoplejía en el centro y la parálisis en las extremidades", citando palabras de Laboulaye. Previamente dijo el gran tribuno: "Los partidarios de la centralización se equivocan en los resultados que esperan. Cometen un error filosófico en sus apreciaciones. La concentración del poder no produce ese vigor y esa mayor vitalidad de un país. Tendrá a su disposición mayor cantidad de elementos, pero la fuerza de éstos se debilitará paulatinamente, porque así se debilita su propia iniciativa y su propia actividad, que es el impulso verdadero del progreso. La centralización, atrayendo a un punto dado los elementos más eficaces, toda la vitalidad de la República, debilitará necesariamente las otras localidades". Cfr. Federalismo y centralización en el discurso de Leandro Alem. La capitalización de Buenos Aires, Buenos Aires, Edición de la Presidencia del H. Senado de Buenos Aires, 1986, p. 97. Este discurso es una notable pieza oratoria, que revela las calidades intelectuales y culturales del gran político, que abogó por el federalismo, el municipalismo y los partidos políticos.

108 Roulet, Elva, op. cit., punto "Hacia el traslado de la capital", pp. 50 y ss. Hubo no sólo propuestas políticas y legislativas, sino también académicas, como las de Manuel Solanet, Adolfo Holmberg y Alejandro von der Heyde Garrigós.

109 Pronunciado el 15 de abril de 1986 en dicha ciudad, capital de la provincia de Río Negro.

D. R. C 2016. UNAM, Instituto de Investigaciones Jurídicas, Boletín Mexicano de Derecho Comparado, núm. 146, pp. 375-418. 
Esta revista forma parte del acervo de la Biblioteca Jurídica Virtual del Instituto de Investigaciones Jurídicas de la UNAM

creado una vasta y compleja red de dificultosas relaciones políticas, económicas y sociales. Leandro N. Alem examinó el tema en famoso debate de la Legislatura bonaerense. Lo ubicó en el mismo sitio trascendente de definición de un sistema político que es necesario reactualizar por tratarse de una visión profética que coincide con el diagnóstico de la actual realidad argentina.

Dicha iniciativa presidencial ${ }^{110}$ prosperó, y el Congreso de la Nación sancionó la Ley 23,512 en 1987, que así lo dispuso para las ciudades de Viedma y Carmen de Patagones, previa cesión efectuada por leyes 2,086 y 10,454, de las Provincias de Río y de Buenos Aires, respectivamente.

Como ya se sabe, dichas leyes no se cumplieron, y la situación se ha agravado, como lo indica la situación actual de nuestro federalismo, según lo expuesto en este trabajo.

Por ello, proponemos nuevamente el traslado de la capital, con base en los argumentos de tipo histórico, político, económico y social que hemos expuesto en este aporte — al analizar la realidad nacional-, a los que se suman los provenientes de la doctrina del federalismo y del derecho comparado que hemos mencionado.

Consideramos imprescindible y urgente descentralizar y desconcentrar el país, con una enérgica voluntad política para cumplir el proyecto federal de la Constitución y mejorar nuestro ordenamiento territorial.

Habrá que discutir nuevamente el futuro emplazamiento de la capital, con base en criterios estratégicos e interdisciplinarios.

Sostengo que el asiento de las autoridades federales debe ser en una ciudad modesta, ${ }^{111}$ lo más alejada posible de los intereses corporativos, para que primen las virtudes republicanas, democráticas y federales, y se pueda pensar en grande el destino de nuestra nación. ${ }^{112}$

110 De trasladar la capital a Viedma-Carmen de Patagones, marchando al sur, al frío y al mar, y que formaba parte de otras iniciativas para profundizar nuestro federalismo, donde también se incluía una reforma constitucional. Cfr. Roulet, Elva, op. cit., p. 53.

111 Así lo sostuvo Félix Luna en su obra ya citada, Buenos Aires y el país, Buenos Aires, Sudamericana, 1982.

112 Ezequiel Martínez Estrada expresó una muy crítica opinión sobre la Ciudad de Buenos Aires como capital federal: “...Las provincias han creído que Buenos Aires, como sede de las autoridades nacionales, era el punto supremo de la aspiración de todos, mientras que Buenos Aires procedió con esos aportes sagrados con un criterio no sólo unitario sino verdaderamente municipal. Se engrandeció, se embelleció, se fortificó, más exclusivamente como urbe y no como Capital Federal" (cfr. La cabeza de Goliat, Buenos Aires, 1940, p. 31 ). 
La actual Ciudad Autónoma de Buenos tiene sus problemas institucionales resueltos por la reforma constitucional de 1994, y gozará seguramente en el futuro de su autonomía plena, como otro miembro más de nuestra Federación. ${ }^{113}$

\section{GONGLUSIÓN}

$\mathrm{Al}$ finalizar la exposición de las veinte propuestas, abogamos nuevamente por el ejercicio de una política arquitectónica, que nos permita cambiar esta realidad deprimente del centralismo, la decadencia y la anomia en que nos encontramos.

Sabemos que no es tarea fácil. Hay que enfrentar poderosos intereses y superar una deficiente cultura constitucional y de la legalidad, que muestran la magnitud y alcance de los desafíos.

Para ello, habrá que apelar a los mejores ejemplos de nuestra historia que nos permitan producir esta verdadera reconstrucción de nuestros valores cívicos, para consolidar el proyecto republicano, federal y democrático de nuestra Constitución Nacional.

113 La Convención Constituyente distinguió los dos temas: el de la Ciudad Autónoma de Buenos y el de la capital federal. Por tanto, si dejara de ser la Ciudad Autónoma la sede de las autoridades federales, mantendrá el status constitucional ya reconocido. Véase nuestra obra ya citada, Federalismo y constitucionalismo provincial, cap. V. 